\title{
DIABETES UK
}

KNOW DIABETES. FIGHT DIABETES.

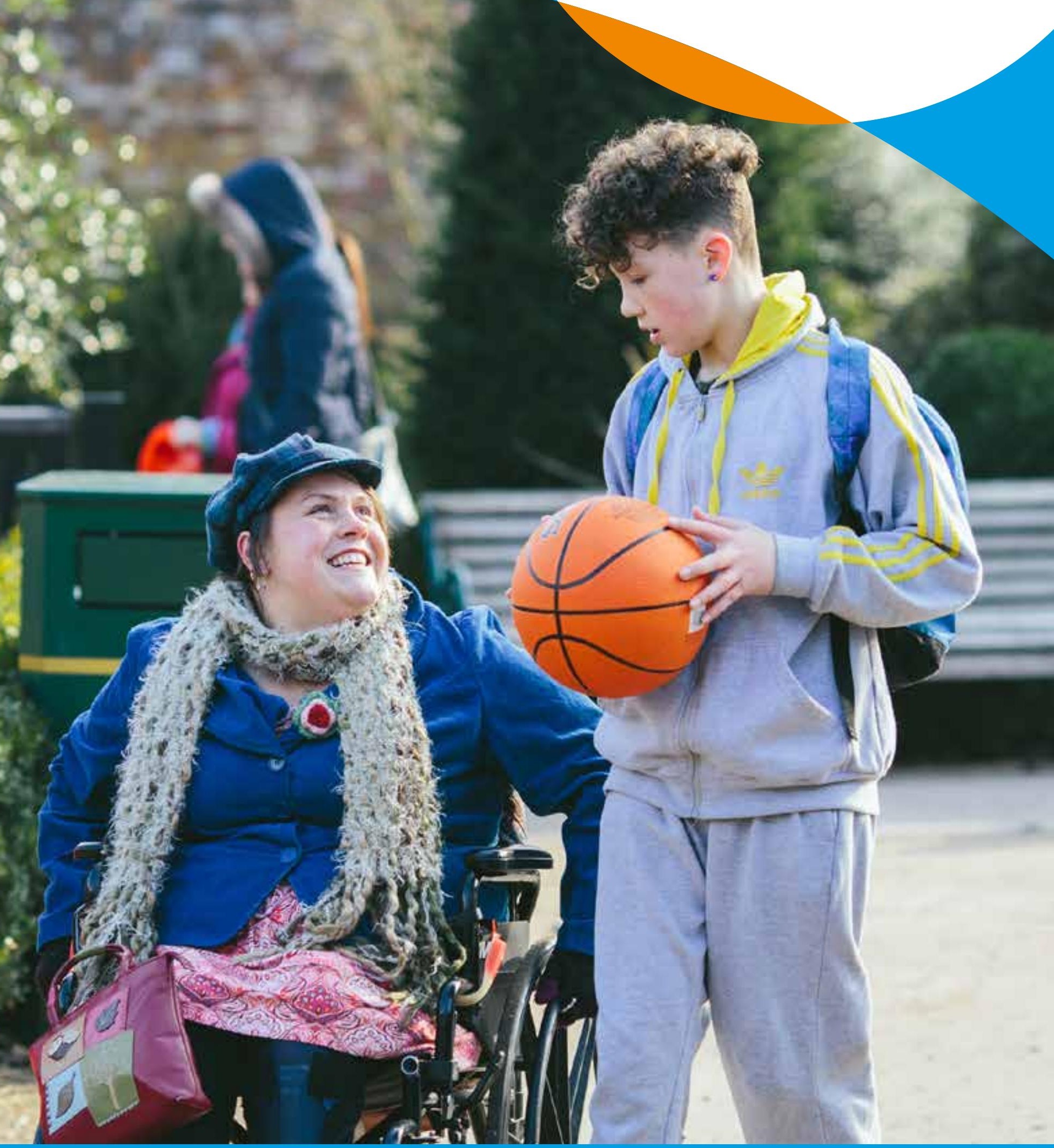

Us, diabetes and a lot of facts and stats

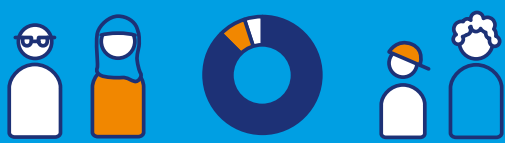

$\%$

\section{Updated November 2019}




\section{Hello}

\section{This is for you. It's designed to make your job easier.}

\section{Whether you've worked here for years or are nosing through this on your first day it will be useful.}

It gives you some of the key facts and stats about diabetes, a basic guide to the condition and how we help people.

As you'll see, diabetes is incredibly rich with data.

Some of the statistics are shocking. Together they make clear how serious diabetes is.

Alone, those statistics can look stark and dismal.

So, when using them we always need to show how we're dealing with these problems. It gives people optimism and reasons to support us.

That's why each section explains what we've done to help people with diabetes, whether it's in the past, today, every day or in the future.

Statistics can sometimes be easy to ignore or difficult to grasp. You need to bring them to life with real stories. Get out there and meet - don't just email or ring people with diabetes. Listen to what they've got to say and use their experiences, our work and these statistics to tell your story.

We'll update this document and the infographics continually. If there's statistics or bits of our work you think are missing, please let us know.

Thanks,

Luke 


\section{How to use this booklet}

\section{The facts and stats}

Almost all the facts and stats here are available for you to use as infographics so you can drop them into your work. Use the number by each infographic to find it on our media library Third Light. Email production@diabetes.org.uk for access to Third Light. You can find the reference for each infographic by looking at the same number at the back of this booklet. This document and the infographics will be constantly updated so make sure you always use a new version for each piece of work so it's accurate.

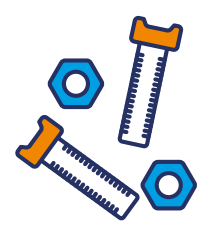

\section{The basics}

This section gives you a brief introduction to the subject. It's been signed off by our Clinical and, Brand and Creative teams so can be dropped into your work as and when you need it.

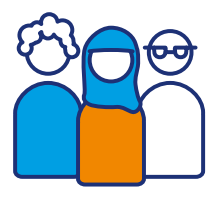

\section{What we do}

Remember we always need to talk about the work we do. These are quick examples and they're far from comprehensive. You can find out more about each piece of work by chatting to the team responsible. Go and say hello.

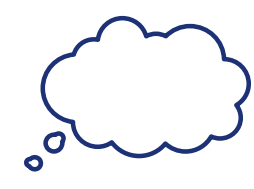

\section{What you need to know}

It's really important we're always accurate with our statistics. There's certain ways some statistics must be presented and certain ways others can't. This section gives you a bit of background about the statistics so you can use them correctly.

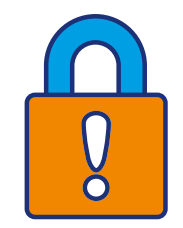

\section{Careful}

These statistics aren't available as infographics on Third Light.

That's because they're especially sensitive or there are complex reasons for them. If you'd like to use them you'll need to have a chat with us first. Email brand@diabetes.org.uk

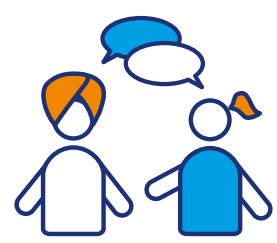

\section{Get your own stories}

"If one man dies of hunger, that is a tragedy. If millions die, that's only statistics." Whether or not Stalin actually said it doesn't matter. The sentiment is true. A single story is often more powerful than vast numbers. There's a lot of vast numbers in this booklet. Make sure your work can't be dismissed as "only statistics". Go out and get stories about people with diabetes and tell them. 

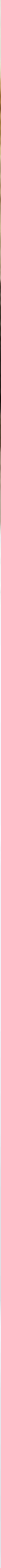


\section{Headline stats}

\section{The basics}

More people than ever have diabetes. And the number of people experiencing complications or dying because of their diabetes is growing too.

We are facing a diabetes crisis.

\section{$0^{\circ}$ What we do about it}

We're fighting for a world where diabetes can do no harm. And as the UK's leading diabetes charity, it's our job to tackle the diabetes crisis. We provide information, advice and support to people with all types of diabetes so they can learn to live well with their condition. And we bring people together so they can learn from each other and get to grips with diabetes. Our campaigns make sure diabetes is at the top of the political agenda and we fight to make sure everyone gets the care they need. Our research builds our knowledge of diabetes, develops improved treatments and will, one day, find a cure. We can only do all this thanks to our supporters whose donations and fundraising make all of our work possible.

\section{What you need to know}

We talk about the number of complications rather than the number of people experiencing them because how they're counted is different. Heart failure, heart attacks and stroke are counted as the number of people experiencing them. But each amputation is counted as a complication, so one person might have several amputations in a year. It's fine to say, "Thousands of people with diabetes experience complications like heart attacks, stroke, and amputations every week." While the actual number of complications experienced is going up we think the percentage of people with diabetes experiencing them is going down, certainly compared to 50 years ago. Because of the limited amount of data collected in the past we can't say this for sure. 


\section{Headline stats}

Infographics available

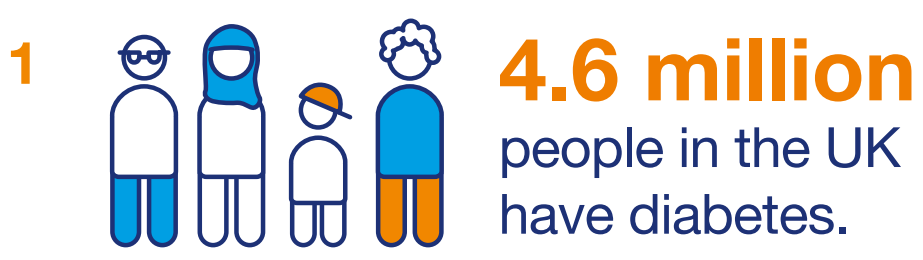

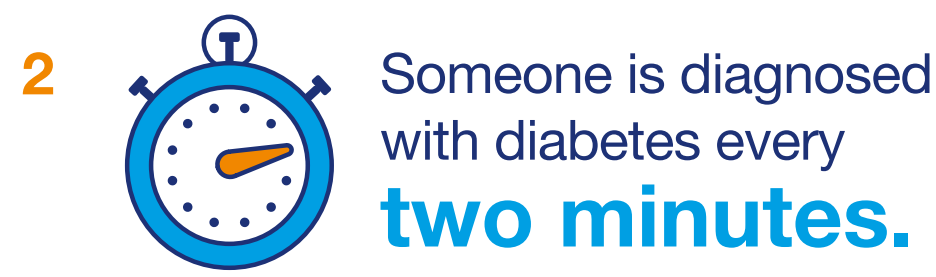

\section{Every week diabetes leads to more than}

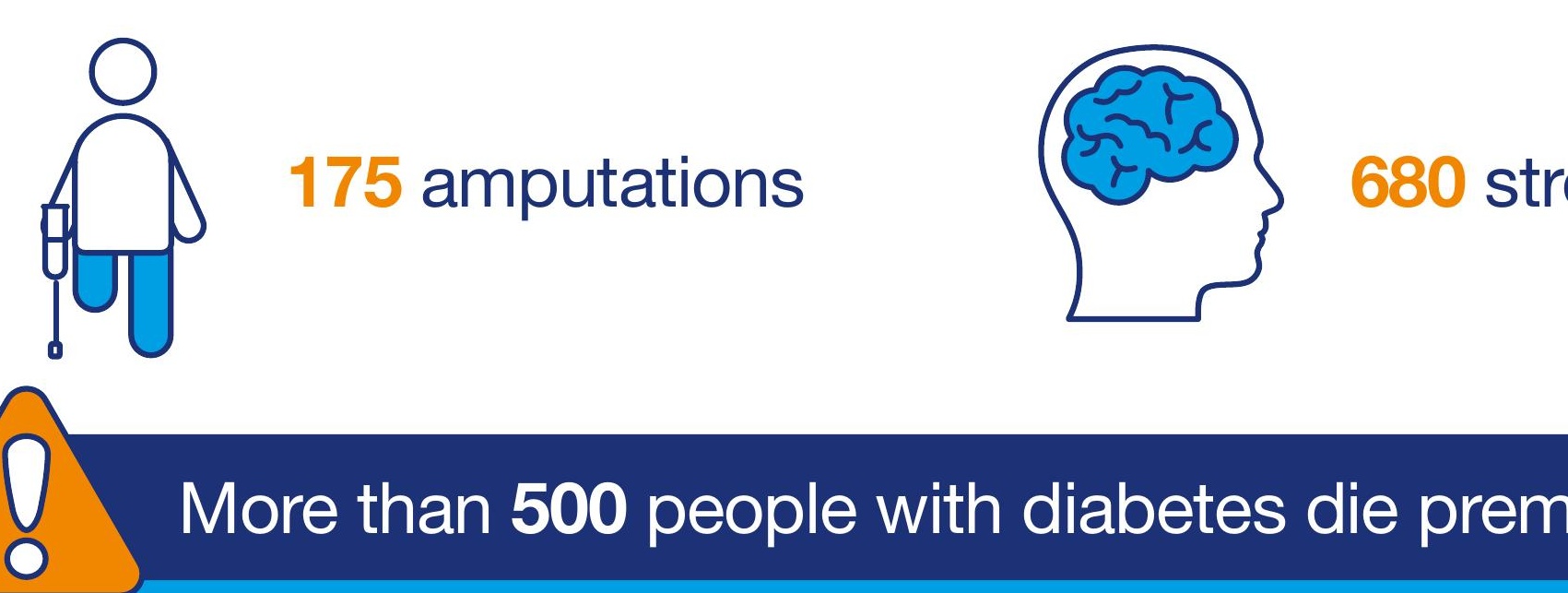




\section{Headline stats}

Infographics available

3

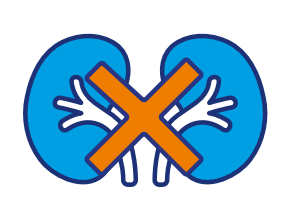

At least 10,350

people in the UK have end stage kidney failure because of their diabetes.

4
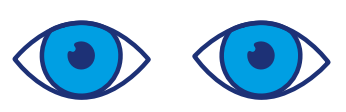

More than 1,700 people have their sight seriously affected by their diabetes every year in the UK.

okes

530 heart attacks and almost 2,000 cases of heart failure. laturely every week. 
$2 x^{\circ}=$ का का

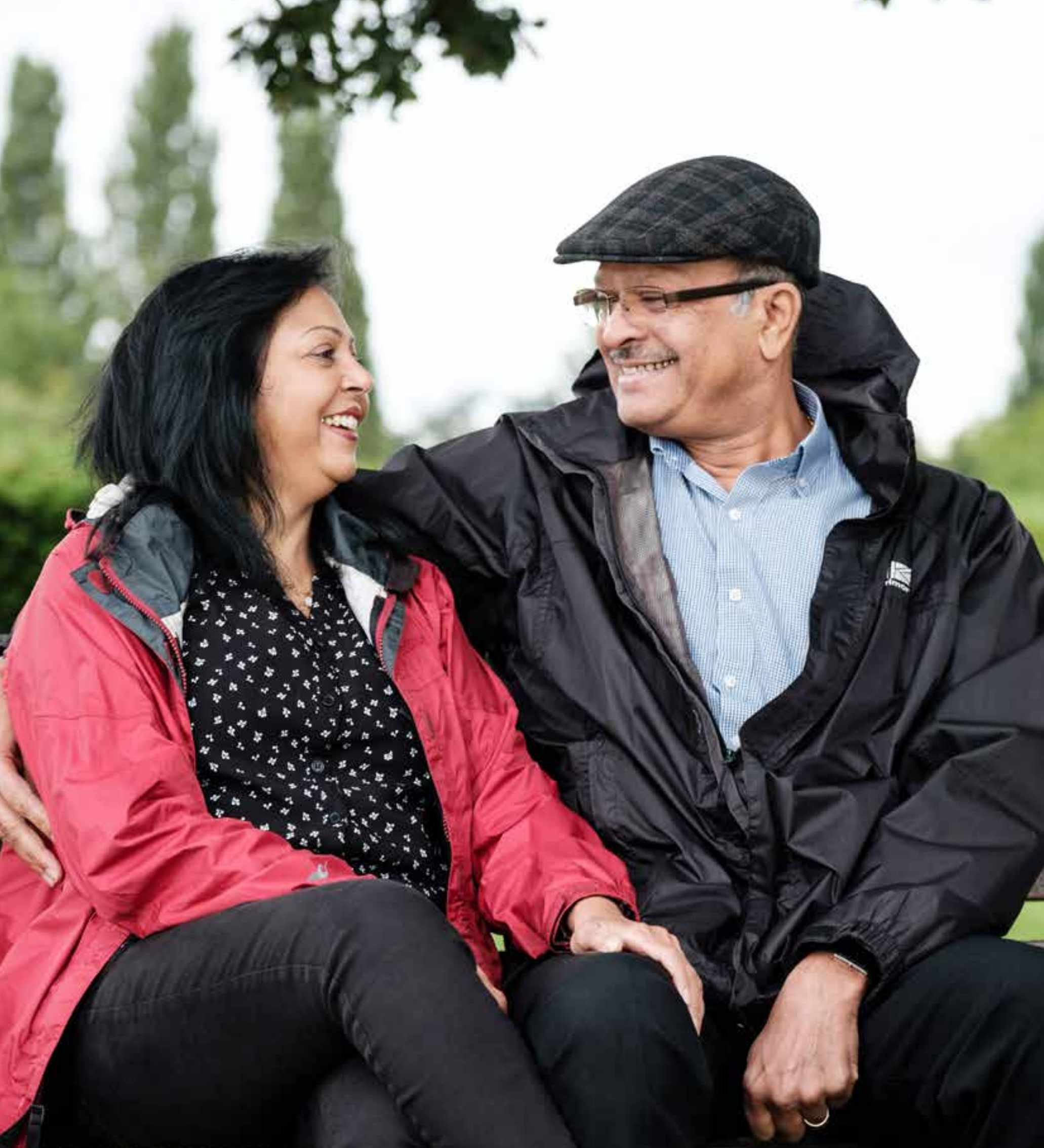




\section{How many people have diabetes}

\section{The basics}

Diabetes is a condition where someone has too much glucose - a type of sugar in their blood. Blood sugar levels are normally controlled by insulin produced in the pancreas. If someone has diabetes, they're either not producing insulin, or the insulin they do produce can't work properly or there isn't enough of it. This means that sugar builds up in their blood and can't get into the cells of their body where it's used for fuel. Too much sugar in the blood can lead to sight loss, amputation, kidney failure, stroke and death.

The dramatic increase in obesity is the main reason there are so many more people living with Type 2 diabetes than 20 years ago.

\section{What we do about it}

We've been helping people with diabetes since 1934. Back then, before the $\mathrm{NHS}$, people had to pay for their own healthcare. HG Wells and Dr RD Lawrence founded us to "give mutual aid and benefit and to promote the study, the diffusion of precise knowledge and the better treatment of diabetics in this country." Since then we've been at the forefront of finding out more about diabetes, sharing knowledge, discovering better treatments, improving the quality of care, and making sure diabetes doesn't get in the way of someone living their life. Together with our supporters, fundraisers, donors, volunteers and campaigners we will build a world where diabetes can do no harm.

\section{What you need to know}

The Secretary of State for Health and Social Care agrees the budget and overall priorities for the NHS in England, whereas the devolved governments have responsibility for healthcare in Scotland, Wales and Northern Ireland. The number of people diagnosed is counted separately in each nation. The number of people who have Type 2 diabetes but are not diagnosed is an estimate. We're able to do this by using the Diabetes Prevalence Model which uses survey data and key demographics like age, sex and ethnicity in the population to estimate the number of people with Type 2 who are undiagnosed. 


\section{How many people have diabetes}

Infographics available

$1280 \begin{aligned} & 4.6 \text { million } \\ & \text { people in the UK } \\ & \text { have diabetes. }\end{aligned}$

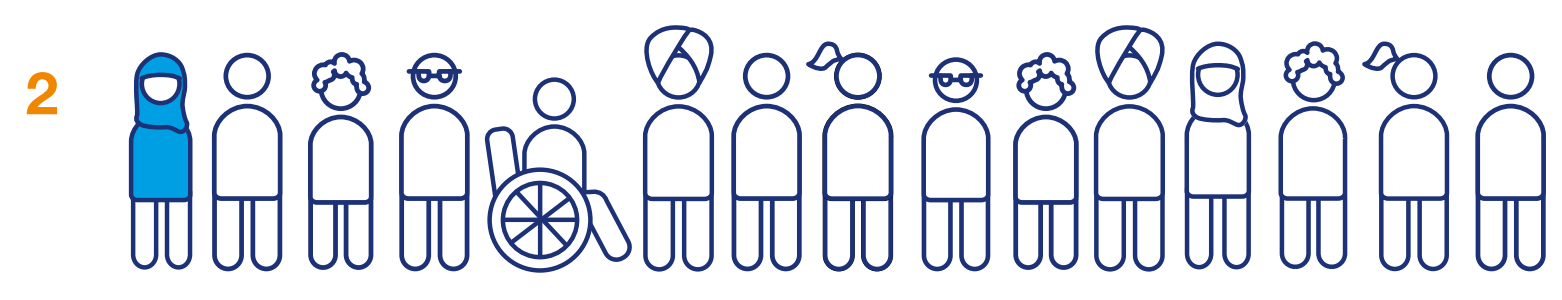

One in 15 people have diabetes in the UK.

Around one million of those people have Type 2 diabetes but have not yet been diagnosed.

\section{The number of people diagnosed with diabetes in}

$\begin{aligned} & \text { England is } \\ & \text { more than } \\ & 3,116,330\end{aligned}$
$\begin{aligned} & \text { Scotland is } \\ & \text { more than }\end{aligned}$




\section{How many people have diabetes}

Infographics available

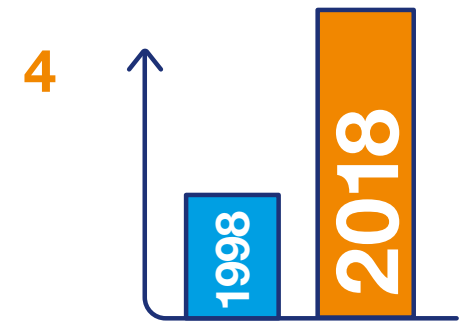

The number of people

diagnosed with diabetes has

more than doubled

in 20 years.

5

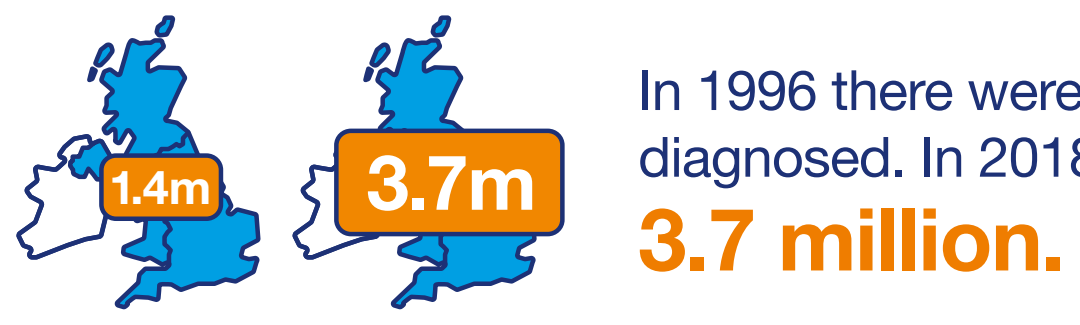

6 All of the people living with diabetes in the UK could fill Wembley Stadium more than

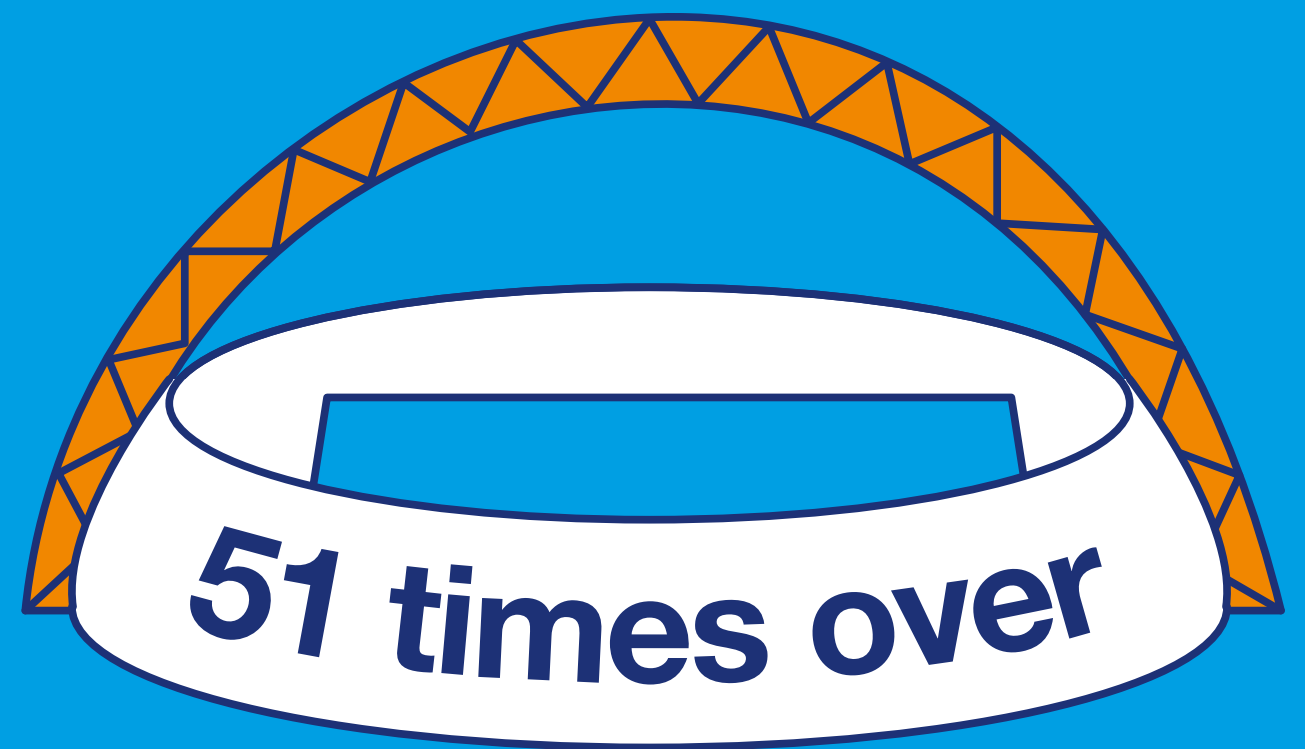




\section{The different types of diabetes}

\section{The basics}

Type 1 develops when the insulin-producing cells in the body have been destroyed and the body is unable to produce any insulin. Everyone with Type 1 needs to treat their diabetes by injecting insulin or using an insulin pump.

Type 2 develops when the body still makes some insulin but it's not able to work properly or there isn't enough. Some people can manage it with a healthy diet, regular physical activity and, if they need to, by losing weight. But the longer someone has Type 2, the more likely it is that they will need medication. About a quarter of people with Type 2 will eventually need to take insulin.

MODY is short for maturity onset diabetes of the young. There are several different types of MODY and they need to be treated differently. Some forms of MODY mean people will need insulin, others can take a drug which allows the insulin they produce to work more effectively. One form of MODY means slightly higher blood sugar levels but requires no treatment. MODY is inherited genetically.

\section{$\overbrace{}^{\circ}$ What we do}

Our research has helped us understand more about why some people are more at risk of Type 1 diabetes or Type 2 diabetes. Our DiRECT research has been able to put the Type 2 diabetes of almost half the people who took part into remission. And we're understanding more about the immune attack that causes Type 1 diabetes so that one day we can stop it happening. Back in the 90s we set up the Exeter Monogenic Diabetes Team. With our funding they have been able to discover different types of MODY. The lab is recognised around the world for its expertise and people with rare types of diabetes now get quicker diagnosis and the right treatment.

\section{What you need to know}

The figures we get about the number of people with diabetes don't differentiate between types of diabetes. We look at the national diabetes audits and Scottish Diabetes Survey to estimate figures for Type 1 and Type 2. But these don't show data on the numbers with more unusual types of diabetes like MODY. 


\section{The different types of diabetes}

\section{Infographics available}

1

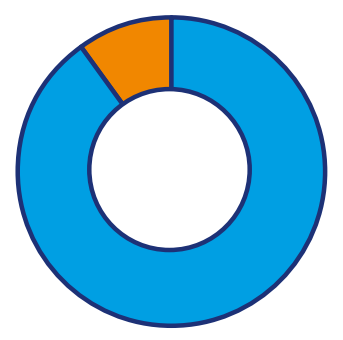

Other types of diabetes include MODY and gestational.
About $90 \%$ of people with diabetes have Type 2.

About $10 \%$ of people with diabetes have Type 1.

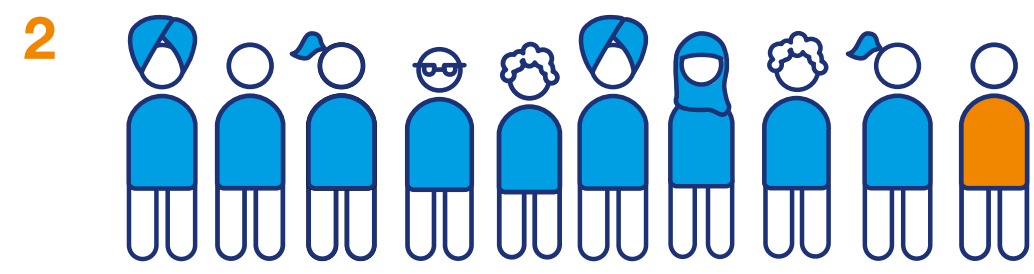

About $90 \%$ of people with diabetes have Type 2. About $10 \%$ of people with diabetes have Type 1.

Other types of diabetes include MODY and gestational. 


\section{Diagnosis}

\section{(o) The basics}

The symptoms of Type 1 diabetes come on very quickly - over a few days or weeks and need urgent treatment. Without it, consistently high blood sugar levels can lead to a condition called diabetic ketoacidosis or DKA for short. This happens when a severe lack of insulin means the body cannot use glucose for energy, and the body starts to break down other body tissue as an alternative energy source. Ketones are the by-product of this process. Ketones are poisonous chemicals which build up and, if left unchecked, will cause the body to become acidic. DKA can kill.

The symptoms of Type 2 diabetes are rarely as obvious and are often put down to old age or not considered serious enough to go to the doctors. But the longer people's blood sugar levels stay too high, the more at risk they are of serious complications.

\section{$\mathrm{R}^{\circ}$ What we do}

Our 4Ts campaign was created to make sure people know the four main symptoms of Type 1 diabetes: tired, thirsty, toilet, thinner. It was created so parents, grandparents, schools and healthcare professionals could test for Type 1 diabetes before a child went into DKA. For parents of newly diagnosed children we have the Type 1 Bag, which helps them get through those first few months and explains how we can help. Our Know Your Risk events and free online tool help people find their risk of Type 2 diabetes. We don't diagnose people but we encourage them to see their doctor if they're at high or moderate risk.

\section{What you need to know}

Along with the 4Ts - toilet, thirsty, tired, thinner - other symptoms of diabetes include infections like thrush, cuts and wounds taking longer to heal and blurred vision. 


\section{Diagnosis}

\section{Infographics available}

1

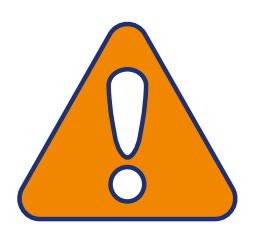

Early diagnosis is vital.

Complications can begin five to six years before some people actually find out they have Type 2 diabetes.

2080

One in three

people will have complications with their eyes, feet, kidneys or nerves by the time they're diagnosed with Type 2 diabetes.

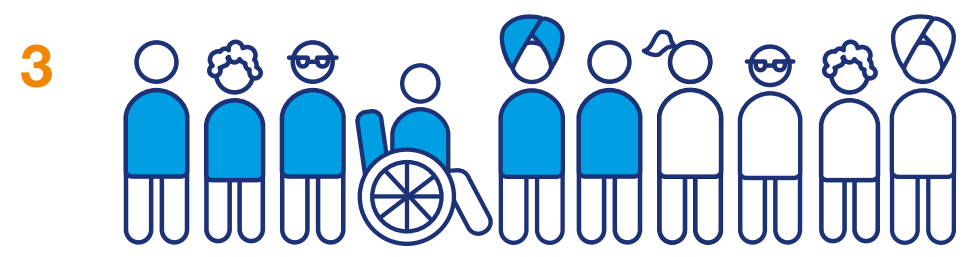

6 in 10 people have no symptoms when they're diagnosed with Type 2 diabetes.

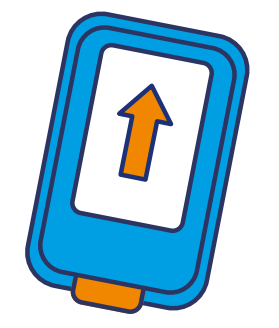

\section{$23 \%$ of children}

are diagnosed with diabetes in

diabetic ketoacidosis (DKA). 

3. 7.5.

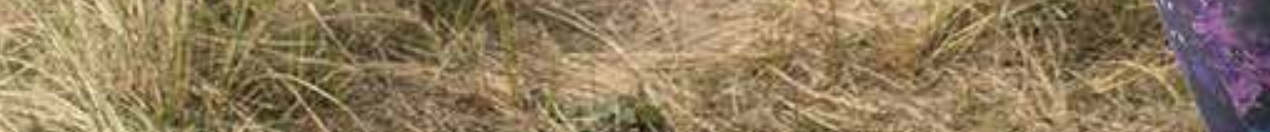

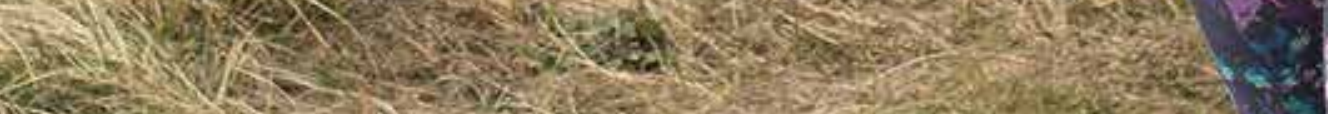

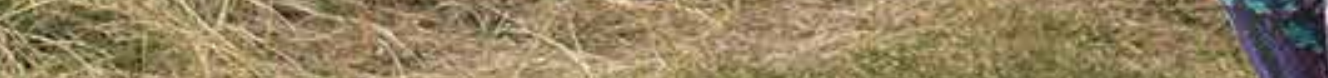
20. She W.

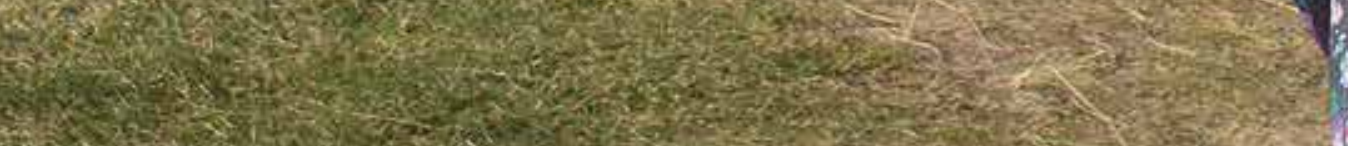

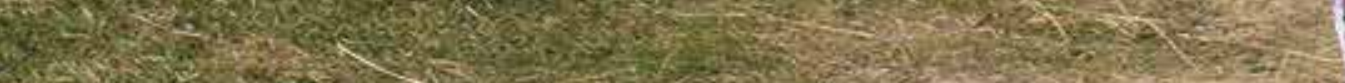

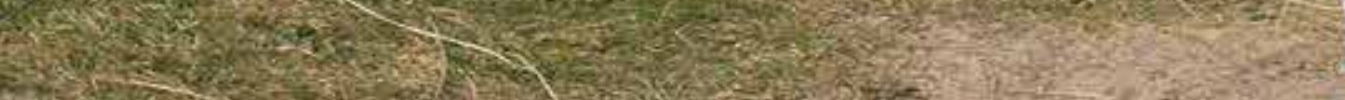
5 -

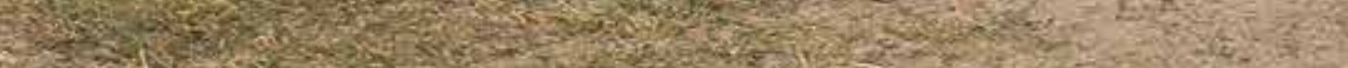
S.

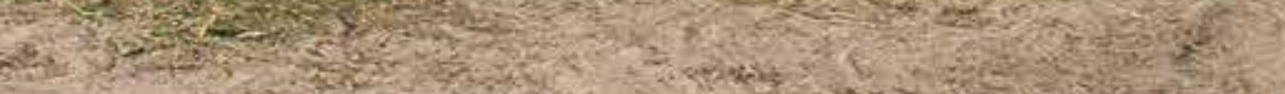
(2015)

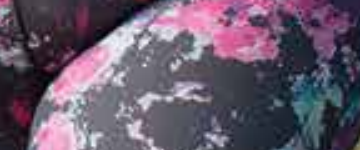

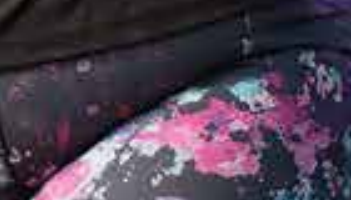

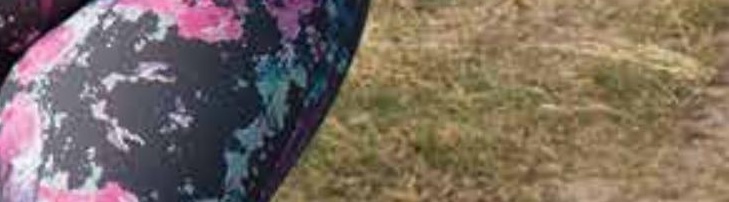

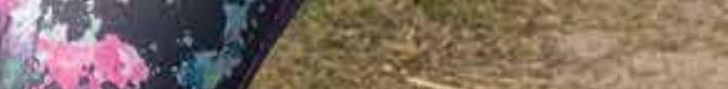
2.

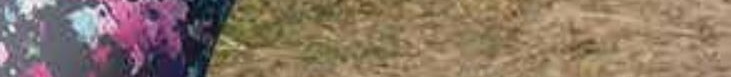
8. 8 (5)

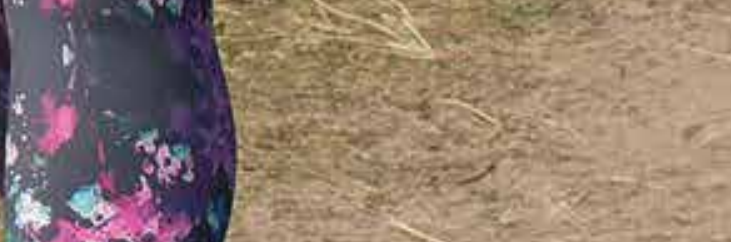
$x^{3}+29$

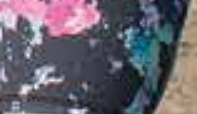




\section{How many people are at risk of Type 2 diabetes?}

\section{The basics}

Your risk of Type 2 diabetes increases the older you get and whether you're a man (slightly more at risk) or a woman. It also increases if you have a close family member with diabetes and if you're from a black or South Asian background. These are risk factors people can't do anything about.

But people's risk of Type 2 diabetes is also increased by being overweight - especially around the belly - and if they have a history of high blood pressure. People can do something about these risk factors by being more active, eating better and losing weight. And it's being overweight that is largely behind the dramatic increase of people with Type 2 diabetes and those at increased risk of it.

\section{What we do}

Our Know Your Risk events and online tool help people find out their risk and what they need to do to reduce it. With NHS England and Public Health England we set up the NHS Diabetes Prevention Programme, which supports people to reduce their risk with tailored support to lose weight and get more active. We campaign for a healthier society and are part of the Obesity Health Alliance who convinced the government to introduce the Sugar Levy. We're now seeking action on better food labelling and the end of marketing junk food to children. Our Community Champions volunteer in communities more at risk of Type 2 diabetes and make them aware of what they need to do to reduce their risk of it.

\section{What you need to know}

Know Your Risk uses a risk score we developed with the University of Leicester and places people in one of four risk groups. The figures for the two lowest risk groups have recently changed. We will also be changing the names of the two highest risk groups because people found them confusing. But for the time being our Know Your Risk tool and volunteer packs still use the older names. For people in the lowest risk, 1 in 100 will get Type 2 diabetes in the next 10 years while for increased risk it's 1 in 35 . For people at high risk, what our online tool calls moderate, it's 1 in 7 people. While 1 in 3 people at very high risk, what our online tool calls high risk, will get Type 2 diabetes in the next 10 years. 


\section{How many people are at risk of Type 2 diabetes?}

\section{Infographics available}

1

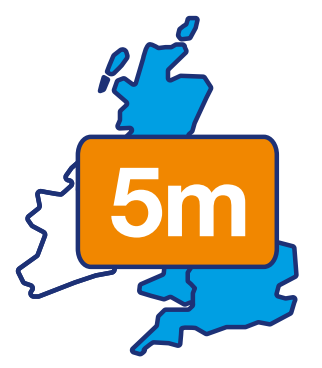

By 2025 we think more than 5 million people will have diabetes in the UK.
$2 \frac{53}{5.5 m}$

By 2030 we think

\section{more than 5.5 million}

people will have diabetes in the UK.

\section{3 million}

people are at increased risk of

Type 2 diabetes in the UK.

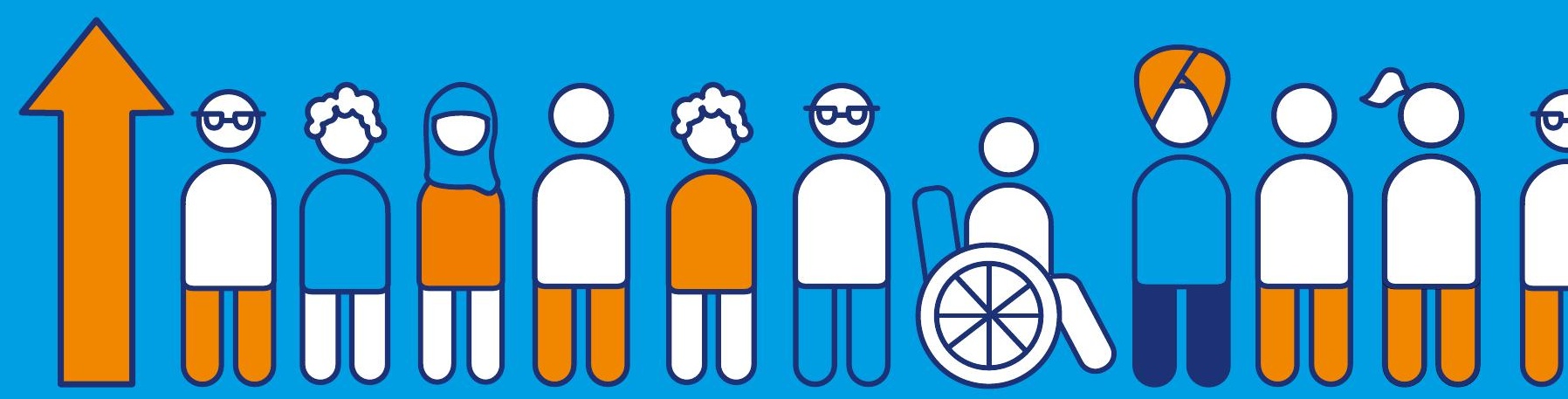




\section{How many people are at risk of Type 2 diabetes?}

\section{Infographics available}

6

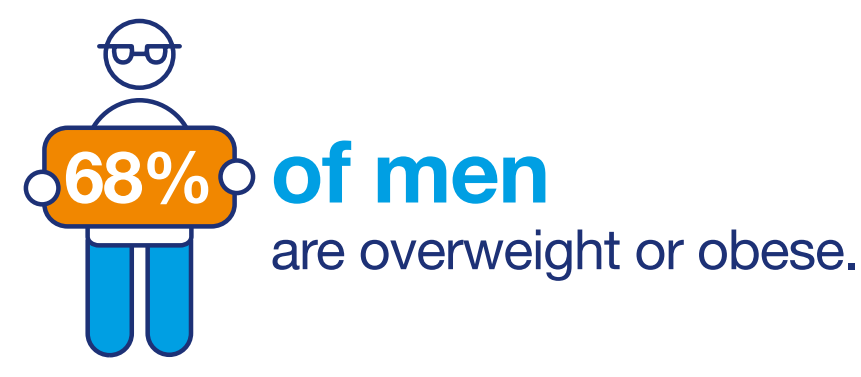

7

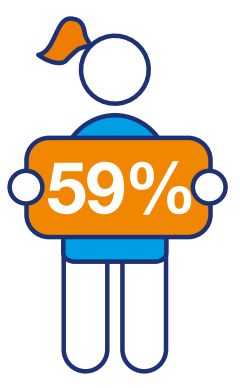

of women

are overweight or obese.

8

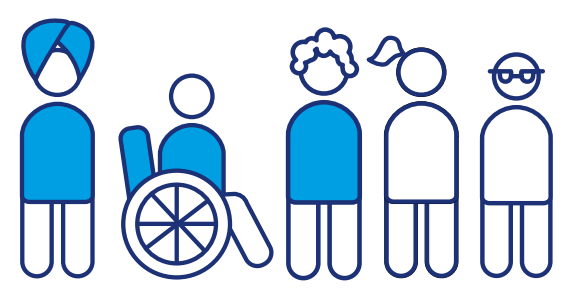

Three out of five cases of Type 2 diabetes can be prevented.

9 South Asian and black people are two to four times more likely to develop Type 2 diabetes than white people. 


\section{How many people are at risk of Type 2 diabetes?}

\section{Infographics available}

$10 \ominus 8$ You are more at risk of Type 2

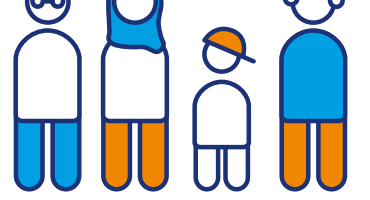
diabetes if you have a close family member who has diabetes.

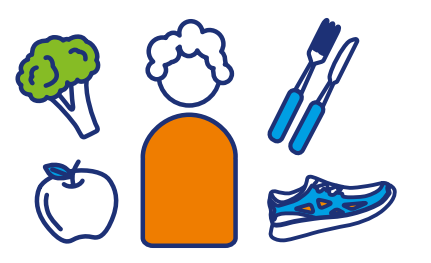

You can reduce your risk of Type 2 diabetes by healthy eating and being more active.

12

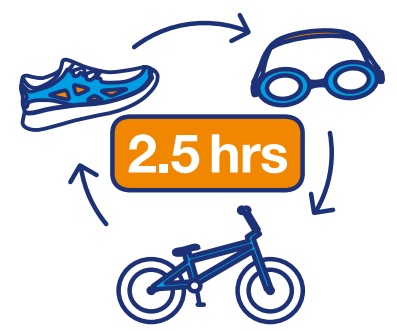

Adults should do two and a half hours a week of moderate activity like swimming, cycling on the flat, or walking.

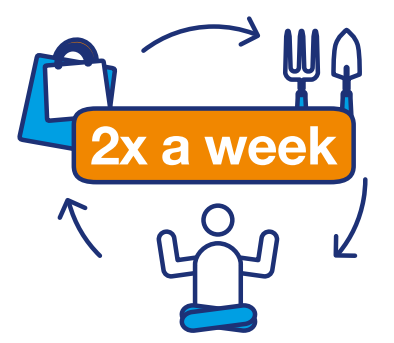

Adults should do activity which improves muscle strength - like carrying shopping, digging in the garden or yoga at least twice a week.
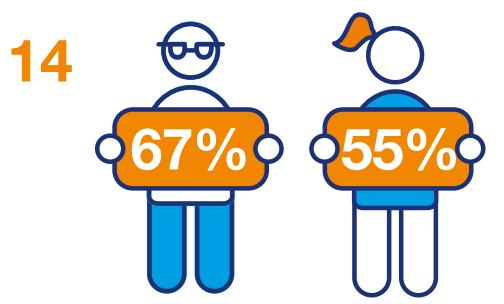

In England and Scotland, only $67 \%$ of men and $55 \%$ of women are meeting recommended physical activity level. 


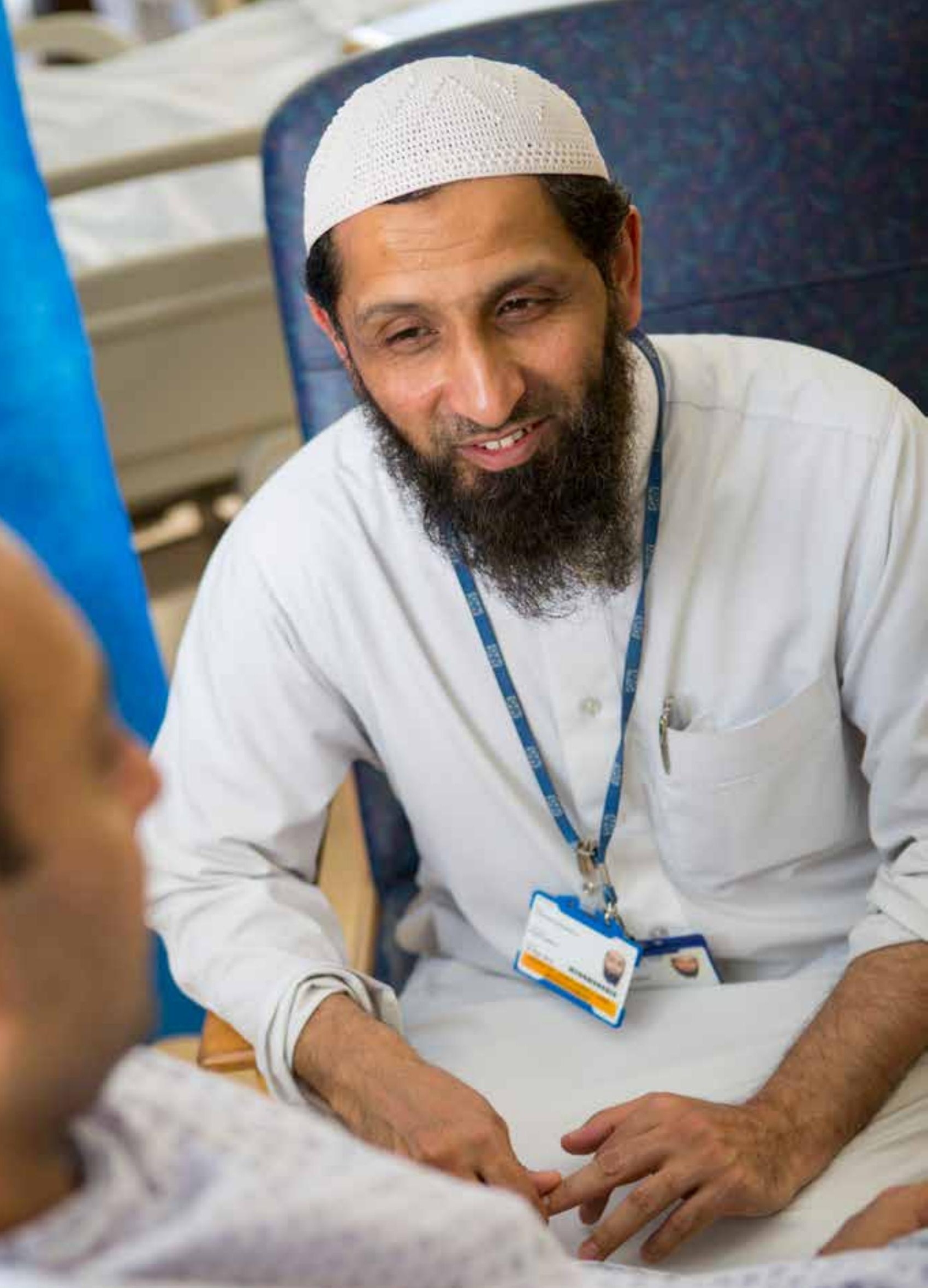




\section{Diabetes and the NHS}

\section{(o) The basics}

The diabetes crisis isn't just a personal one. Along with how it affects people and their families, the NHS is in danger of being overwhelmed by diabetes. It's expensive. With so much being spent on complications, there has never been a more important time to make sure people with diabetes get the support they need to manage their condition and that we do more to prevent Type 2.

\section{What we do}

We made the case for NHS England to spend a further $£ 44$ million on a diabetes transformation fund, which is being spent on improving care to reduce the number of people experiencing complications. A similar $£ 1.7$ million fund has been made available in Northern Ireland. The Diabetes UK Professional Conference brings together thousands of healthcare professionals and researchers to share the best ways to improve care. We also have a team collecting examples of the best care for people and sharing them across the NHS. Our Clinical Champions Programme develops clinicians to lead changes in diabetes care local to them. In 2015 we successfully campaigned to end the unfair prescription fines thousands of people with diabetes were handed. Those fined were refunded. 


\section{Diabetes and the NHS}

\section{Infographics available}

1

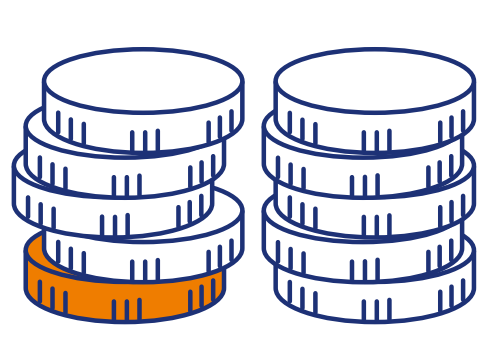

The NHS spends at least

$£ 10$ billion a year

on diabetes.

\section{That's $10 \%$ of its entire budget.}

2

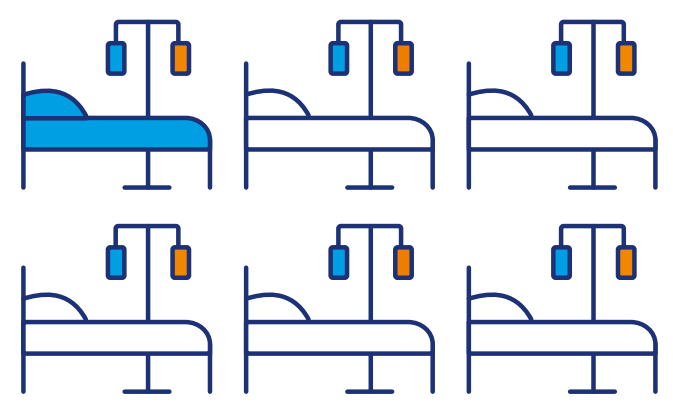

One in six

people in a hospital bed

has diabetes.

3

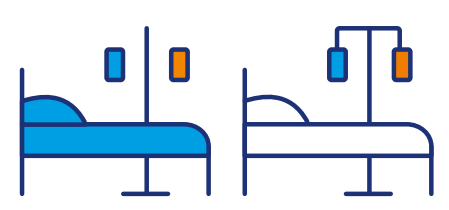

In some hospitals over

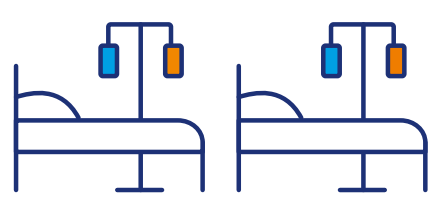

a quarter of beds

are used by people with diabetes. 


\section{Diabetes and the NHS}

\section{Infographics available}

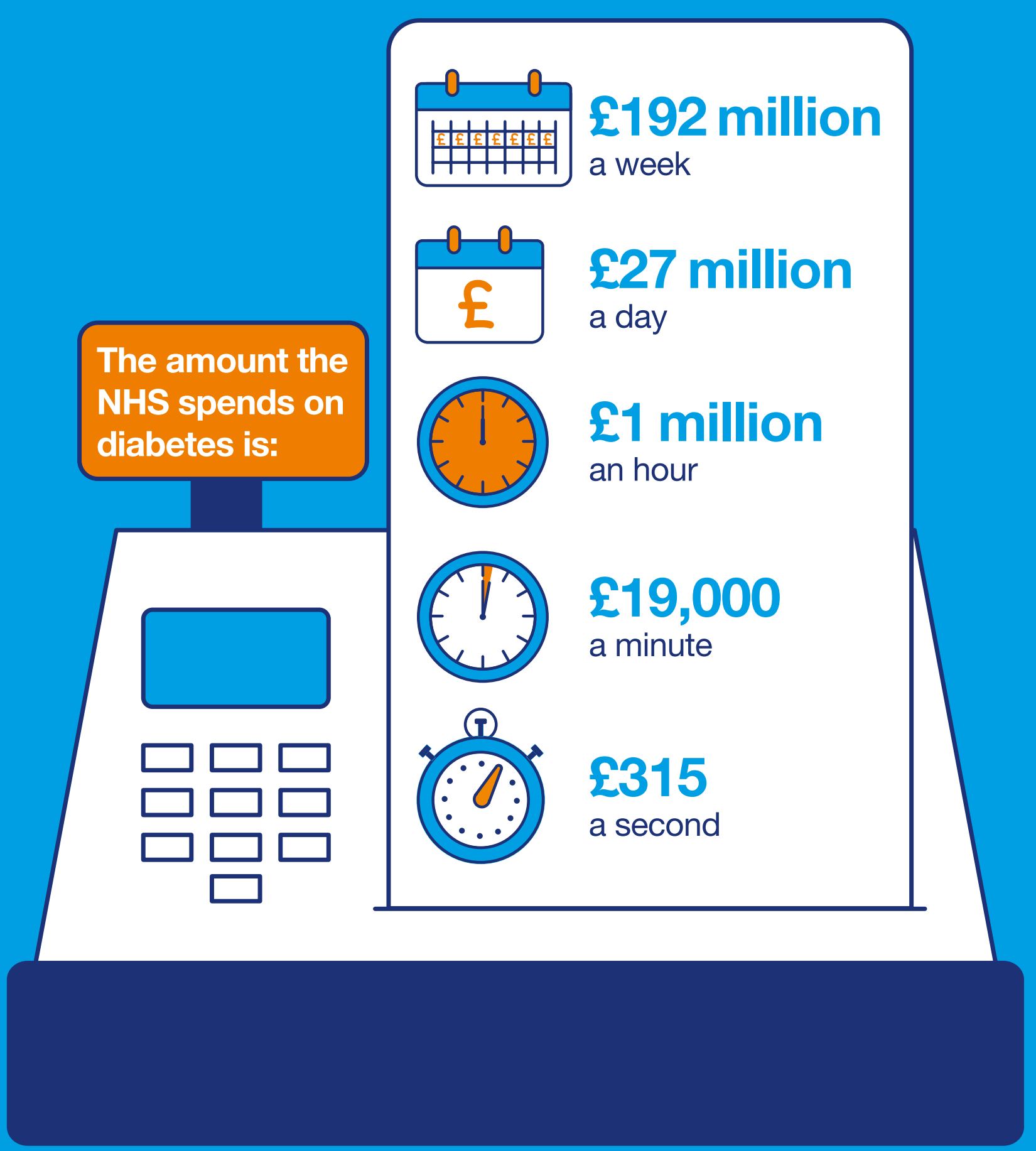




\section{Diabetes and the NHS}

\section{Infographics available}

5

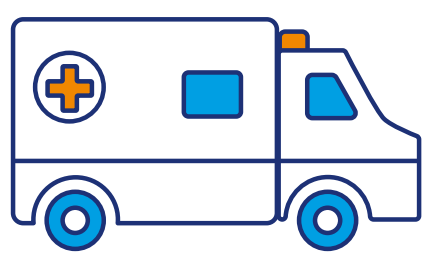

People with diabetes are

twice as likely

to be admitted to hospital.

6

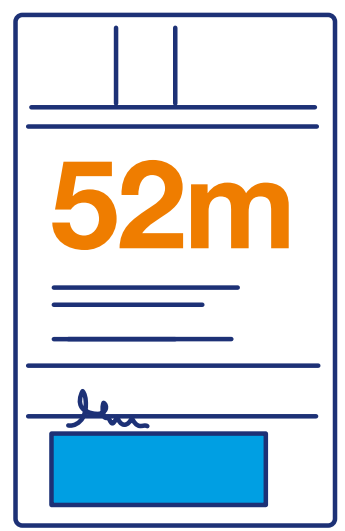

In 2016/17 there were 52 million items prescribed for people with diabetes.

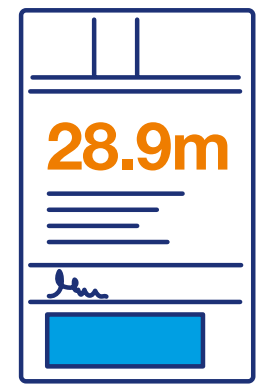

This increased from 28.9 million prescription items 10 years earlier.

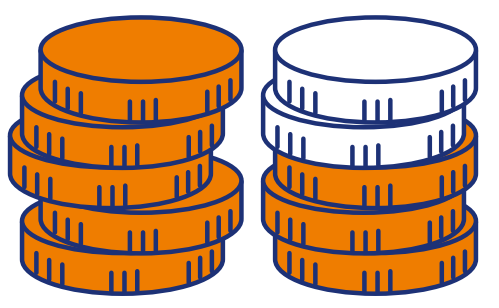

Almost $80 \%$

of the money the NHS spends on diabetes is on treating complications. 


\section{Diabetes and the NHS}

\section{Infographics available}

8 In one year the diabetes transformation fund has led to an extra:

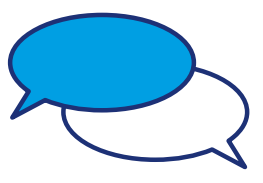

94,000

places on

education courses

being available
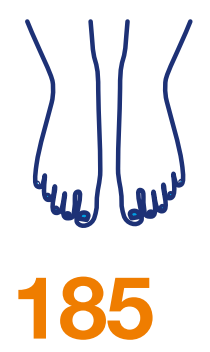

staff appointed

to footcare teams

across 80 hospitals

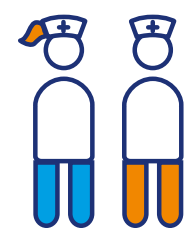

96

inpatient specialist

nurses and related

staff in inpatient teams. 


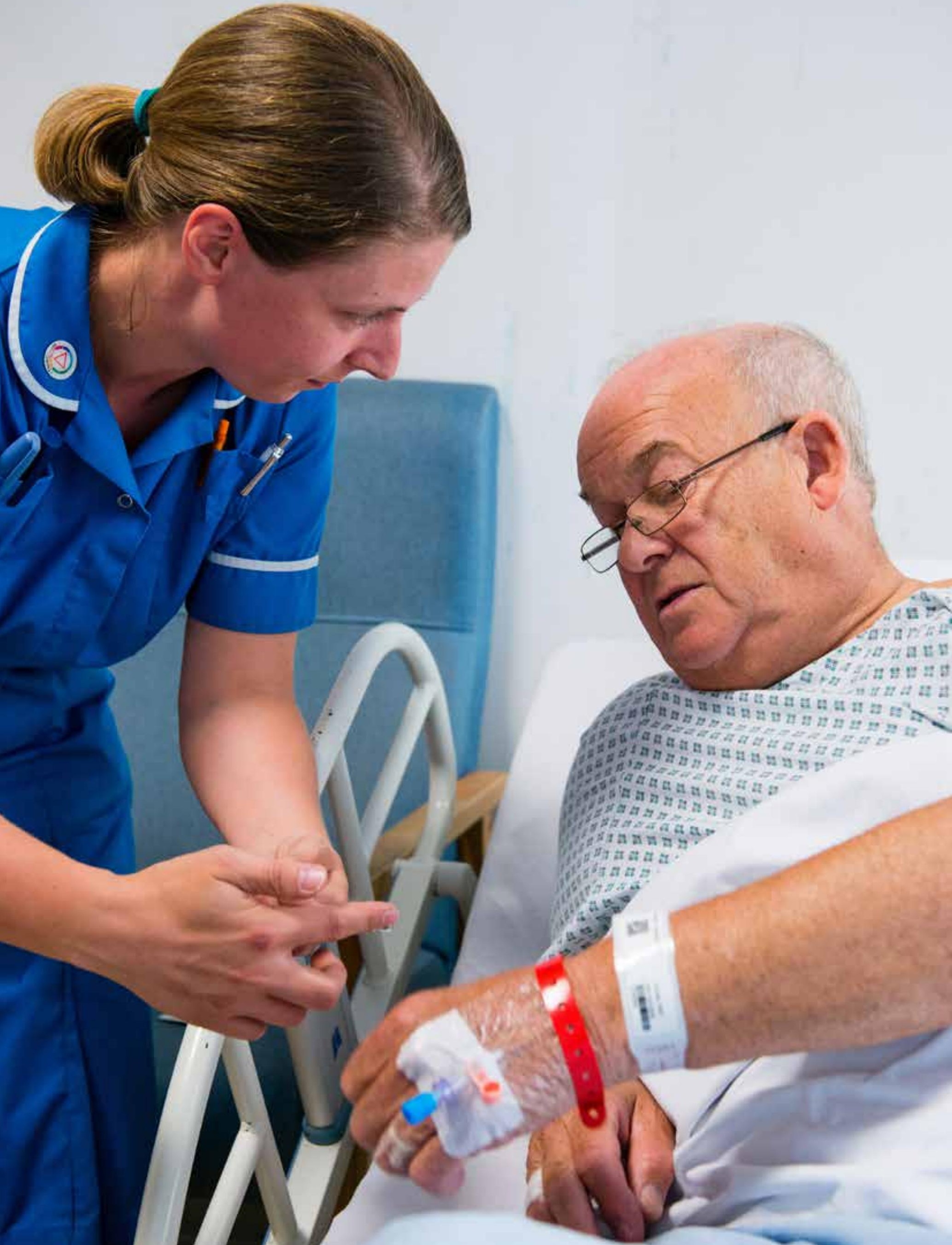




\section{Heart attacks, stroke and cardiovascular disease}

\section{(o) The basics}

People with diabetes are more at risk of heart attack, heart failure and stroke because of damage to the heart and blood vessels caused by high blood sugar levels over a long period of time. Also having high blood pressure, high cholesterol and smoking increases people's risk of these cardiovascular complications. By quitting smoking, moving more, eating better and taking all their medication correctly, people can reduce their risk of heart attacks, strokes and heart failure. Everyone with diabetes should get their cholesterol, blood pressure and blood sugar levels checked each year.

\section{Shat we do}

From 1977 to 1990 we helped fund a huge study called the UK Prospective Diabetes Study. 5,000 people with Type 2 diabetes took part in the trial which showed that improved blood glucose levels and blood pressure reduced complications. At the end of the trial, the overall risk of complications affecting small blood vessels dropped by a quarter. 30 years on, follow-up results showed a positive impact on the risk of eye and kidney complications, heart attacks and death. Another piece of our research which changed the way Type 2 diabetes was treated was a trial called CARDS. It showed that statins - a cholesterol-lowering drug - could reduce the risk of people with Type 2 diabetes experiencing a heart attack by a third and a stroke by almost half. 


\section{Heart attacks, stroke and cardiovascular disease}

\section{Infographics available}

1 Compared to people without diabetes, people with diabetes are

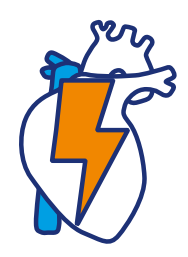

nearly 2.5 times more likely to have a heart attack

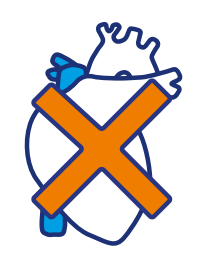

more than 2.5 times more likely to

experience heart failure

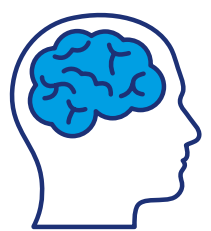

2 times more likely to have a stroke.

\section{Every year diabetes causes more than}

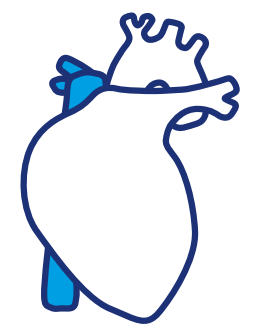

27,000 heart attacks and almost 100,000 cases of heart failure 


\section{Heart attacks, stroke and cardiovascular disease}

Infographics available

2 Compared to people without diabetes, people with Type 1 diabetes are

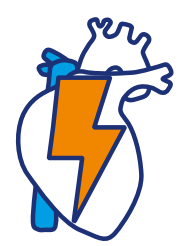

More than 4 times as likely to have a heart attack

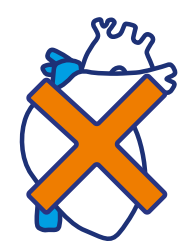

\section{5 times}

more likely to

experience heart failure

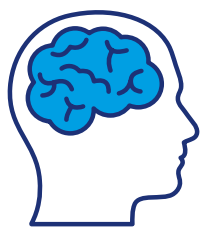

3.5 times more likely to have a stroke. 


\section{Heart attacks, stroke and cardiovascular disease}

Infographics available

4 Compared to people without diabetes, people with Type 2 diabetes are

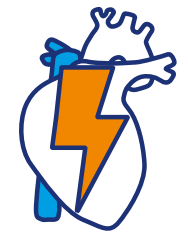

Nearly 2.5 times more likely to have a heart attack.

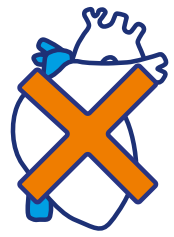

More than 2.5 times as likely to experience heart failure.

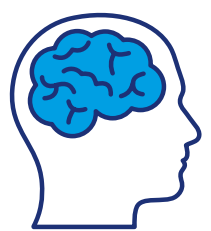

2 times as likely to have a stroke.

\section{Every week diabetes causes more than}

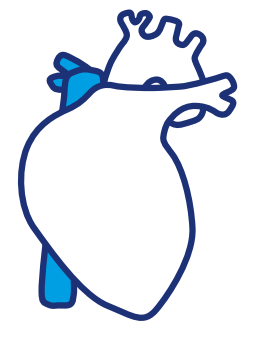

530 heart attacks and almost

2,000 cases of heart failure 


\section{Heart attacks, stroke and cardiovascular disease}

Infographics available

5

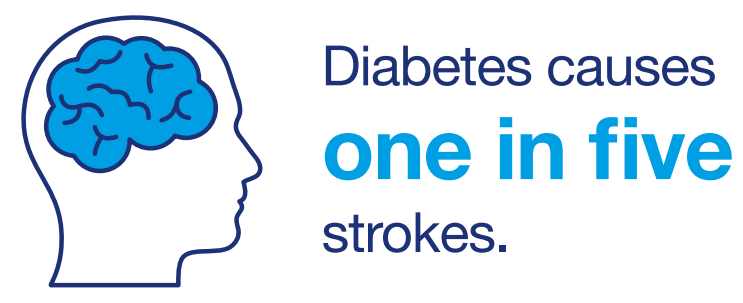

6

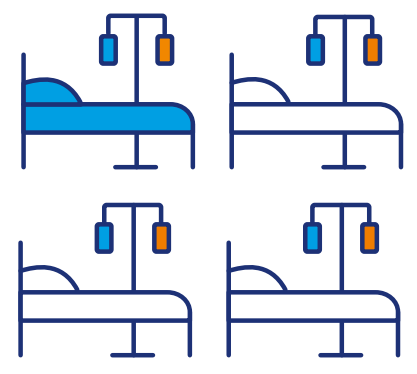

One quarter

of people who end up in hospital because of a stroke, heart attack or heart failure have diabetes.

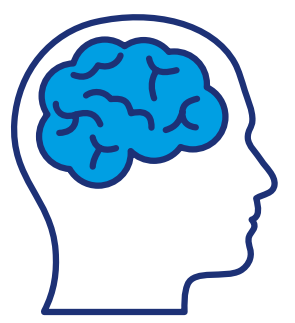

680 strokes. 


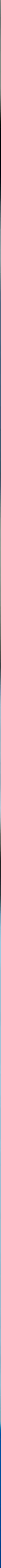




\section{Amputations}

\section{(o) The basics}

People with diabetes are more at risk of foot problems because high blood sugar levels over a long period of time lead to nerve and blood vessel damage. Nerve damage means people stop feeling pain in their feet so might not realise if they've cut or burned themselves. Blood vessel damage makes it harder for the body to heal itself. Even small cuts and burns can lead to ulcers and infections, which can end in an amputation. This is why people with diabetes should check their feet every day, go to their annual foot check and get urgent treatment if they develop any foot problems.

\section{What we do about it}

We set up the UK's first ever diabetic foot clinic in 1981 at King's College Hospital, London. After three years the number of major amputations had halved. Nearly 40 years on we continue to work with the NHS to improve footcare. Our Shared Practice and Policy teams work closely with NHS managers and clinicians to make sure hospitals have the right teams in place so they can prevent amputations. Our Putting Feet First campaign explains how people can take care of their feet. In the research world we're looking to speed up and improve the treatment of foot ulcers. We're also funding research into new treatments for a diabetic foot complication called Charcot foot, which causes the bones in the foot to collapse.

\section{What you need to know}

We're not exactly sure why so many people die so soon after an amputation. We think it's because if someone needs an amputation it's is often a sign of an extremely damaged cardiovascular system. This means they will also be at increased risk of other complications like heart attacks, heart failure and stroke. People might not get the right treatment or care because they delay getting a foot problem looked at or they're not referred to a specialist quick enough. A minor amputation is below the ankle, so could be a whole foot or any number of toes or part of a foot like the heel. A major amputation is above the ankle.

\section{Careful}

Please check with Brand and Creative before using the stats with this icon. Think about who your work is for. 


\section{Amputations}

\section{Infographics available}

1 Diabetes leads to more than $9,150 \mathrm{leg}$, toe, or foot amputations every year.

\section{That's more than 175 a week.}

2

Someone with diabetes is

\section{0 times more likely}

to experience an amputation than

someone without diabetes.

Diabetes causes:

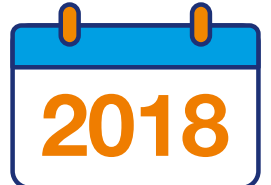

9,155 amputations per year

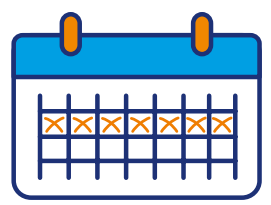

176 amputations per week 


\section{Amputations}

Infographics available

\section{Around half}

of all people who experience a major

8 amputation will die within two years.

\section{More than four in 10} die within five years.

5 Studies suggest that between 70,000 and 90,000 people with diabetes have a foot ulcer in any given week.

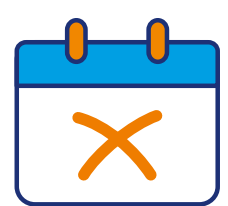

25 amputations per day

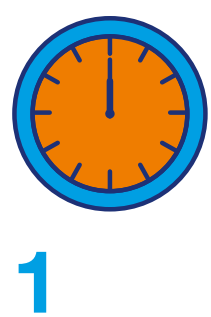

amputation per hour. 


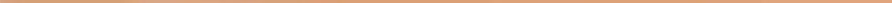




\section{Sight loss}

\section{(o) The basics}

People with diabetes experience eye problems because high blood sugar levels, blood pressure and cholesterol over a long period of time damage the blood vessels in the retina. Eventually the retina - the seeing part of the eye - gets damaged. It's called retinopathy and can lead to sight loss. Retinopathy has no obvious symptoms in the early stages and a lot of damage can be done before someone notices any sight loss. The early stages of retinopathy can be reversed if people can lower their blood sugars and blood pressure. Later stage retinopathy can be slowed down by treatment and can prevent sight loss. Everyone with diabetes should have a photograph taken of the back of their eyes regularly, and every year if any damage is detected.

\section{$0^{\circ}$ What we do}

In the 1980s we funded Professor Roy Taylor to set up a mobile eye screening service in Newcastle. By taking photos of people's eyes and analysing them on the spot he was able to screen more people and get them any treatment they needed. After Professor Taylor showed his screening method was more practical and effective than other methods he also showed it worked on a large scale. We then campaigned for a nationwide eye screening programme for people with diabetes which was rolled out in 2002. By 2009 Newcastle was the first place in the UK where diabetes wasn't the leading cause of sight loss in the working age population. That effect is now spreading across the UK. Other research projects we are funding are looking at improving treatment of retinopathy, limiting its damage and detecting it even earlier.

\section{What you need to know}

Retinopathy doesn't always affect eye sight. While almost everyone with Type 1 might experience some degree of retinopathy it doesn't mean everyone will experience sight loss. People with sight loss are split between being severely sight impaired or sight impaired. Being partially sighted means you still have some vision but you can't see well enough to drive. 


\section{Sight loss}

\section{Infographics available}

1

- More than 1,700

people have their sight seriously

affected by their diabetes every

year in the UK.

\section{That's more than $\mathbf{3 0}$ people every week.}

2

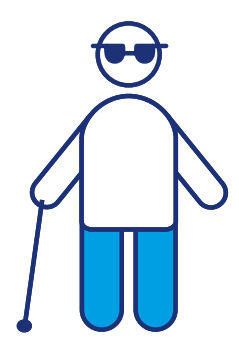

Diabetes is responsible for

\section{$5 \%$ of all sight loss}

in the UK.

$37 \%$ of people

with newly registered sight loss have diabetes in England and Wales.

4 Diabetes is one of the leading causes of preventable sight loss in the UK.

$5 \quad 14 \%$ of working age people who have severe visual impairment have diabetes. 


\section{Sight loss}

\section{Infographics available}

6

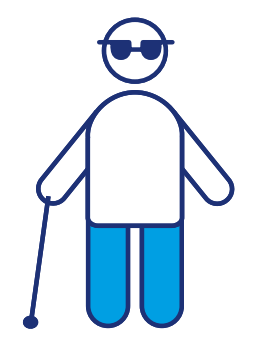

Diabetes makes you one and a half times more likely to get glaucoma and three times more likely to get cataracts. Both can lead to sight loss.

7 की

\section{Almost half}

of people with Type 1 diabetes have some form of diabetic retinopathy.

8808

\section{More than a quarter} of people with Type 2 diabetes have some form of diabetic retinopathy.

9 After $\mathbf{2 0}$ years of living with diabetes almost:

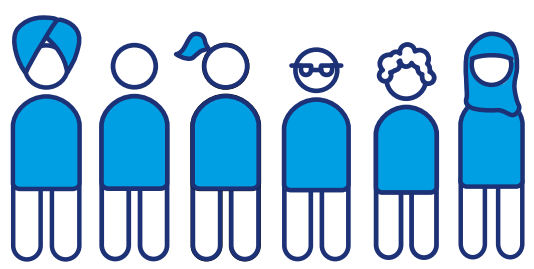

everyone with Type 1 will have some degree of retinopathy.

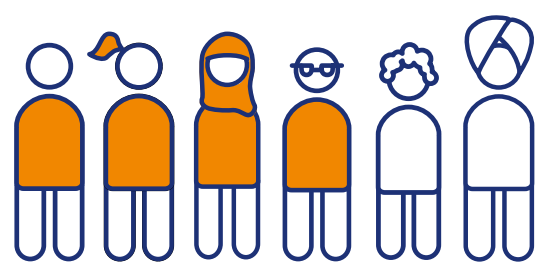

two thirds of people with

Type 2 will have some degree of retinopathy. 


\section{Kidney disease}

\section{(o) The basics}

Kidney disease is called nephropathy or renal disease. It's caused when high blood sugar levels damage blood vessels in the kidneys. It develops slowly over many years so it usually affects people who've had diabetes for a while. Catching kidney damage early means it can be treated. If it hasn't been caught early or the damage gets worse then people can eventually require kidney dialysis or a transplant. This is called kidney failure or end stage renal disease. Everyone with diabetes should have their blood and urine checked each year to check for any problems with their kidneys.

\section{What we do}

Professor Harry Keen qualified as a doctor on the day the NHS was established. He became one of the world's leading diabetes researchers. We were alongside him the whole way. In 1964, with our funding, he developed a way to screen people with diabetes for kidney failure. What he discovered still forms the basis of the urine test we use today to screen for kidney disease. Since 1964 our research has continued to hunt for new ways to prevent and treat kidney failure.

\section{What you need to know}

We don't have a weekly figure for kidney failure because it's an ongoing problem. Once someone needs kidney dialysis they're on it for life or until they a get a transplant. This means it doesn't make sense to divide it into weeks like we can do with other complications. We have such varying figures for kidney problems because of the way they are counted. The UK Renal Registry only counts people whose reason for being on there is recorded as diabetes. This means people might be recorded as having another contributing factor or not even counted at all. 


\section{Kidney disease}

\section{Infographics available}

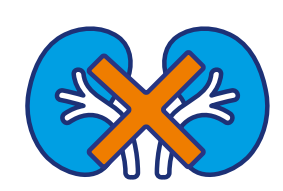

\section{At least 10,350}

people in the UK have end stage kidney failure because of their diabetes.

2 ध

More than one in three people who need kidney dialysis or a transplant have diabetes.

3280

Almost one in five people with diabetes will need treatment for kidney disease during their lifetime.

4 We think there are more than

\section{2,650 people}

in the UK who need dialysis or a kidney

transplant because of their diabetes.

5 People with diabetes are

five times more likely

to need either kidney dialysis or a kidney transplant. 


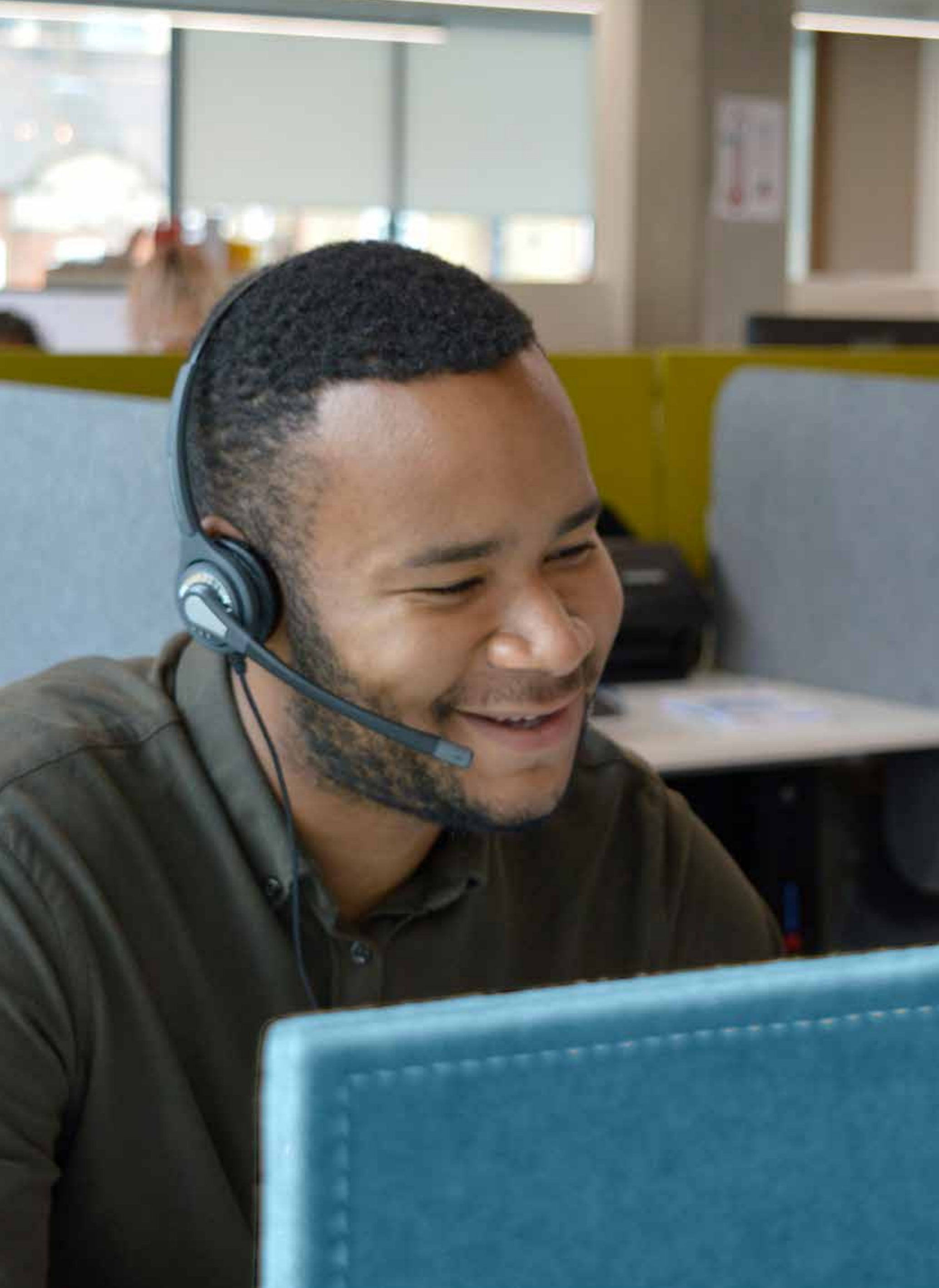




\section{Mental health and depression}

\section{(o) The basics}

Living with diabetes is tough. It never stops. And managing it, for the most part, is down to the person who's living with it. Someone newly diagnosed with Type 2 might have to deal with changing their lifestyle and breaking habits they've had for decades. Others with Type 2 will have to cope with a diagnosis and immediately deal with a complication. People with Type 1 need to get their insulin right every single meal. They might need to adjust it for exercise, how they're feeling, whether they're ill or even just because of the weather. Getting this right all the time is impossible. Some people with Type 1 get anxiety because of their fear of hypos. A lot of people feel guilt, always wondering if there's more they can be doing. There's lots more reasons why someone with diabetes might experience mental health problems.

\section{$\overbrace{}^{0}$ What we do}

We're there for people. Our helpline provides emotional support to anyone with diabetes who gets in touch. Our local support groups bring people with all types of diabetes together to offer each other support and advice, and share experiences. The Diabetes UK Support Forum does the same thing, with thousands of people ready to answer questions, listen and offer tips morning, noon and night. Even talking about mental health problems on social media can help. It means people know they're not the only one having trouble and encourages people to be open about what they're going through.

\section{What you need to know}

There's a difference between having depression and diabetes and depression which is caused by diabetes. And they need to be treated differently. Mental health problems caused by diabetes are commonly known as diabetes burnout. What diabetes burnout means is different to different people. Some people will feel completely fed up and exhausted about managing their diabetes. Others might stop engaging with it by not checking their bloods or going to appointments, while others might stop taking their medication. 


\section{Mental health and depression Infographics available}

1

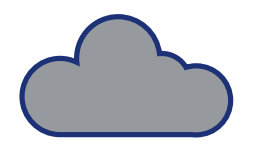

People with diabetes are twice as likely to suffer from depression. And are more likely to be depressed for longer and more frequently.

\section{7 in 10}

people feel overwhelmed by their diabetes.

3 Three quarters of people who feel overwhelmed by their diabetes said it affects how well they manage it.

4 Only $30 \%$ of GPs feel there is enough emotional and psychological support for people with diabetes. 


\section{Mental health and depression}

Infographics available

5

More than 33\%

calls and emails to our helpline

are about emotional support.

6 Someone's risk of Type 2 diabetes is increased by $60 \%$ if they have depression.

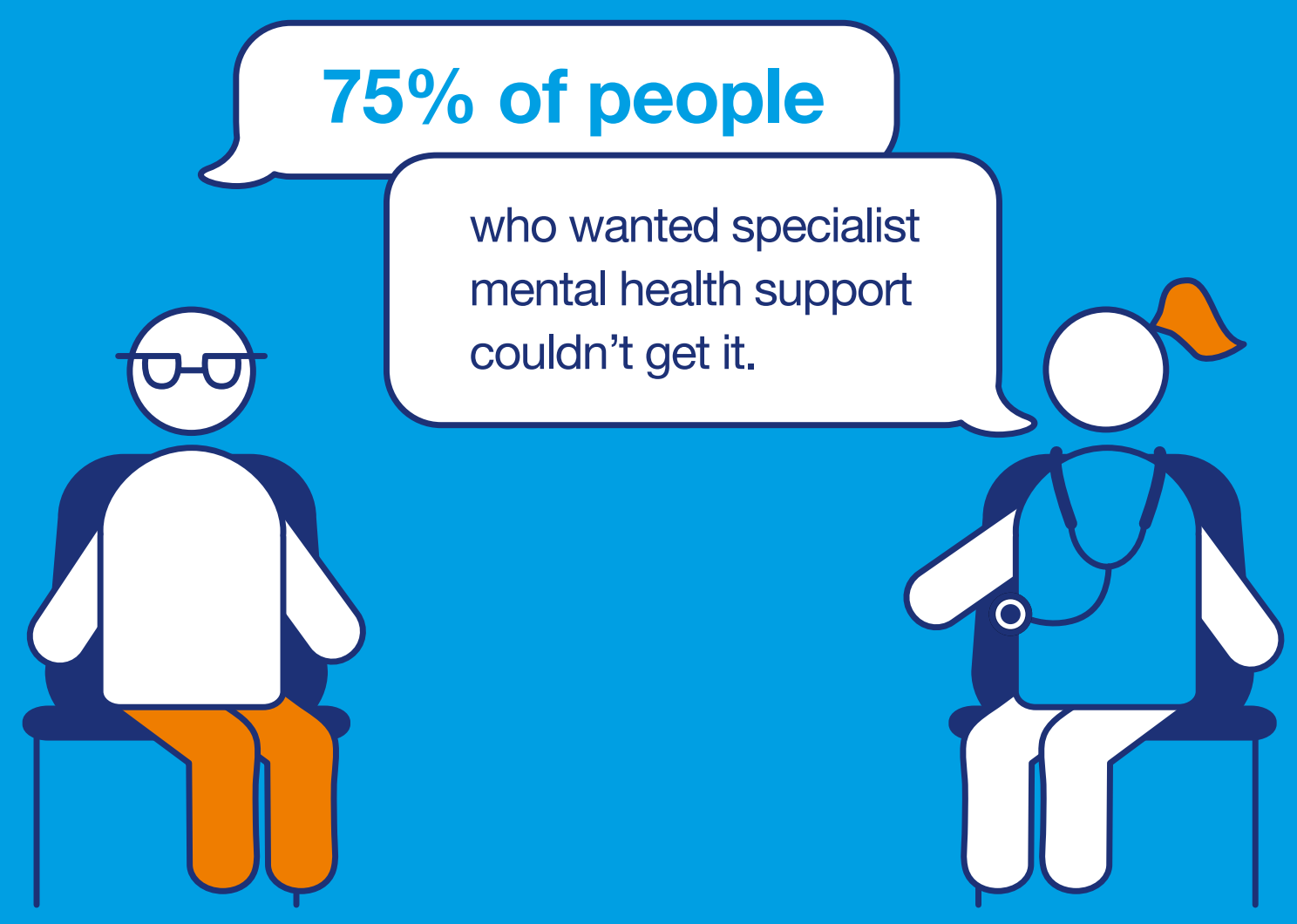




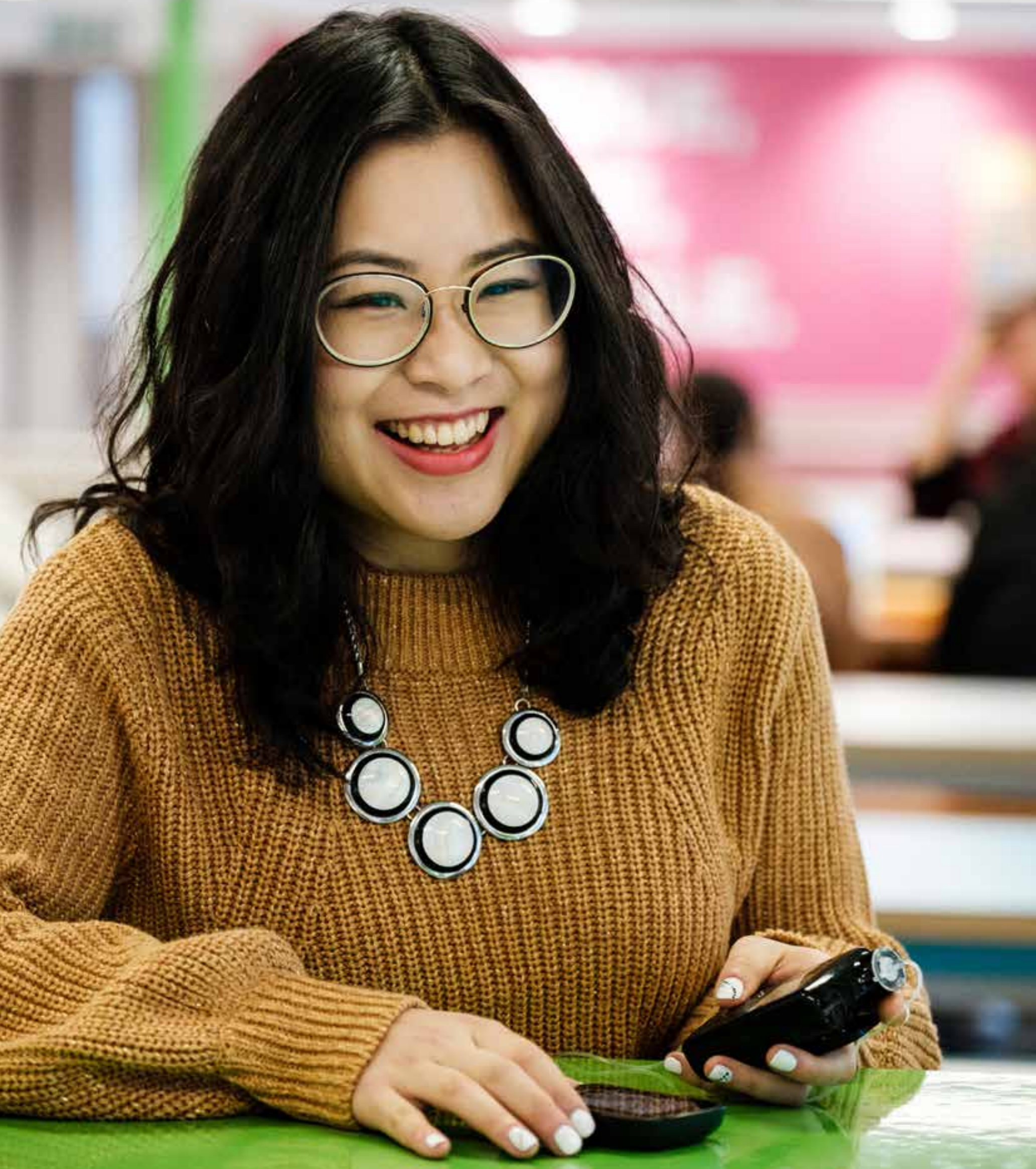




\section{Management of diabetes}

\section{The basics}

People have to manage their diabetes themselves. There's a lot to learn about living with it, it's complicated, and someone's diabetes can change over time. Getting it right more often than not isn't simple. People with diabetes are given a target for their blood sugar levels. They're a little higher than someone without diabetes but not by much. The more often they're in this safe range, the better they generally feel and the lower their risk of complications. But lots of different things affect blood sugar levels and what works one day, might not work the next.

\section{$0^{\circ}$ What we do}

We help people get to grips with their diabetes, whether it's through our events or the information and support we give on our helpline and website. In 2000 we funded a team to design the DAFNE course, which helps people with Type 1 diabetes get their insulin right and adjust it to how they want to live their life. The extra money we campaigned for the NHS to spend on diabetes in England and Northern Ireland is partly going towards getting more people on diabetes education courses. On our website people with diabetes can understand more about their condition by using our free Learning Zone. It tailors information, giving people the knowledge they need for their life, when they need it. Our Community Champions work with their local communities to offer information and support about living with diabetes.

\section{What you need to know}

The number of people meeting treatment targets is a little complicated. NICE is the National Institute for Health and Care Excellence. They give advice and guidance to the NHS about the standard of care people should be getting and the outcomes they should be achieving. NICE says people with Type 1 or Type 2 should have a HbA1c (someone's average blood glucose level over three months) of under $48 \mathrm{mmol} / \mathrm{mol}$ (6.5\%). For people with Type 2 who are on medication it is $53 \mathbf{~ m m o l} / \mathbf{m o l}$ (7.0\%). People who do not have diabetes will have a $\mathrm{HbA} 1 \mathrm{c}$ of under $42 \mathrm{mmol} / \mathrm{mol}(6 \%)$. NICE also recommends people with diabetes have a blood pressure of $140 / 80$ and a cholesterol of $4 \mathrm{mmol} / \mathrm{l}$ (which is a lower target than people without diabetes). The stats we use about treatment targets for this page are actually from the National Diabetes Audit which sets them slightly higher. So it's likely even fewer people are meeting the NICE targets than stated. Whatever the statistics, the lower someone's HbA1c, cholesterol and blood pressure the more they reduce their risk of complications. 


\section{Management of diabetes}

\section{Infographics available}

1

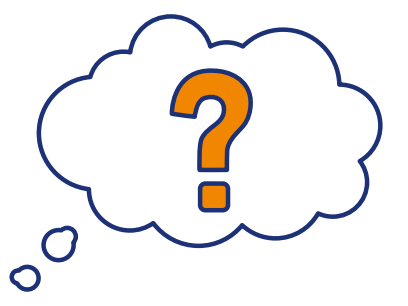

Over two thirds

of people don't fully

understand their diabetes.

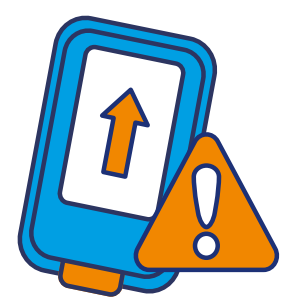

$15 \%$ of people with Type 1 and $6 \%$ of people with Type 2 have exceptionally high blood glucose levels, putting them at serious risk of complications.

38 की

Fewer than one in five

people with Type 1 diabetes are meeting the recommended treatment targets that will reduce their risk of complications. 


\section{Management of diabetes}

\section{Infographics available}

48000

\section{Almost three in five}

people with Type 2 diabetes are meeting the recommended treatment targets that will reduce their risk of complications.

5 People who go on diabetes education courses
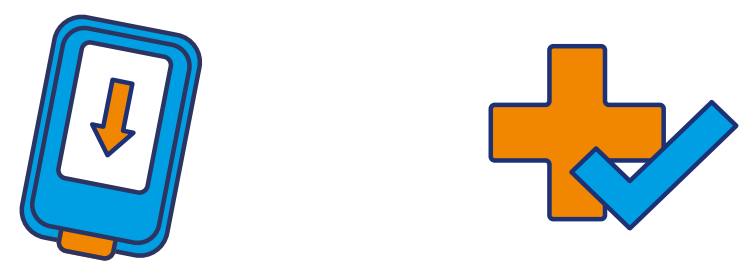

have lower blood improved health glucose levels,

\section{and fewer complications.}




\section{Management of diabetes}

\section{Infographics available}

6 DAFNE, a diabetes education course for people with Type 1:

$\checkmark$ reduces time spent with blood glucose levels at dangerously high levels

$\checkmark$ reduces people's blood glucose levels

and means fewer serious hypos.

8 People with diabetes spend around three hours with a healthcare professional every year.

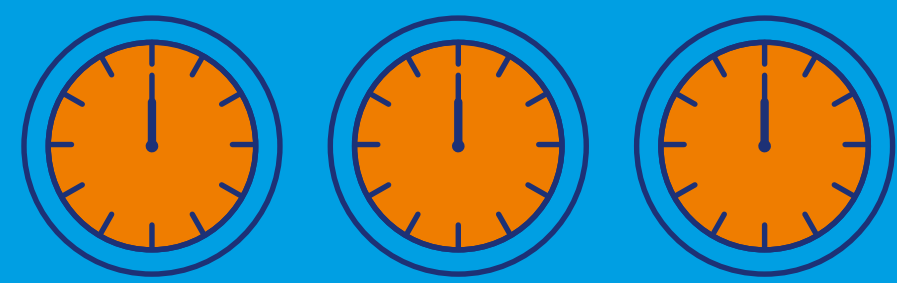




\section{Management of diabetes}

\section{Infographics available}

7 The X-PERT course:

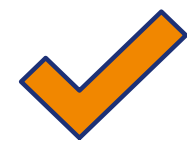

increases people's diabetes

self-management skills and confidence

$\checkmark$ improves their blood glucose levels

$\checkmark$ and reduces cardiovascular risk factors.

For the remaining $\mathbf{8 , 7 5 7}$ hours they must manage their diabetes themselves.

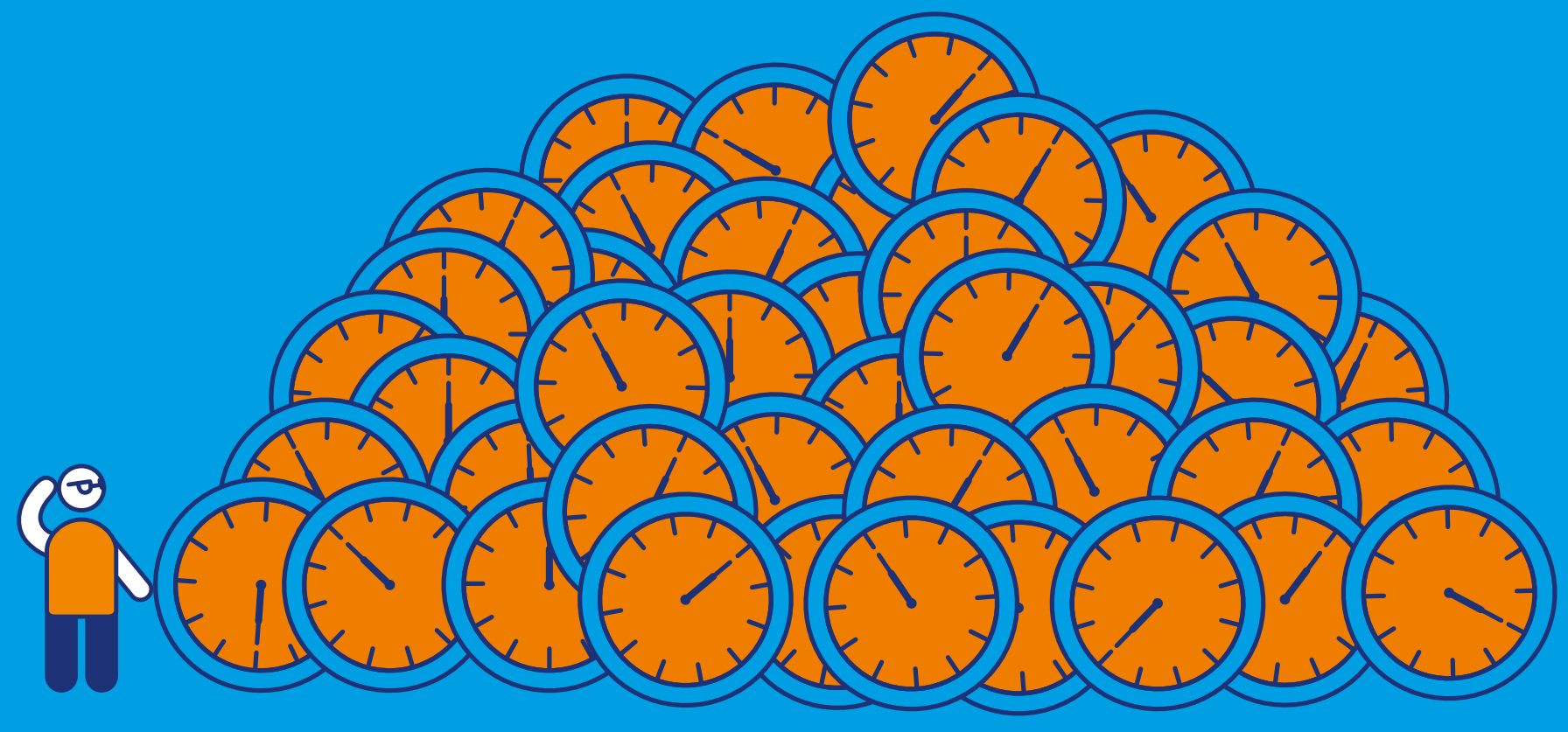



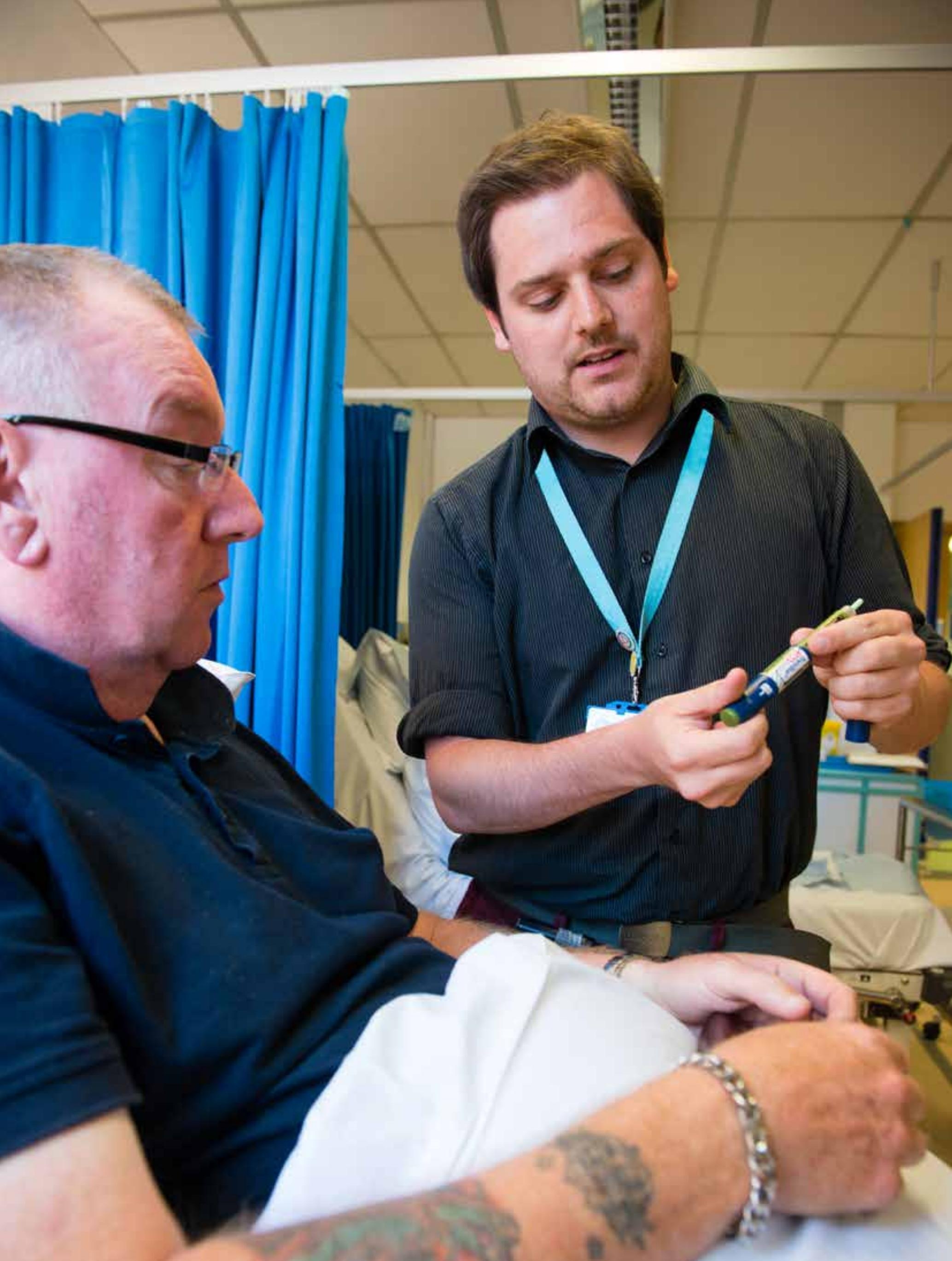


\section{Diabetes care and care in hospitals}

\section{The basics}

There are eight checks that every person with diabetes should get every year. These are things like $\mathrm{HbA} 1 \mathrm{c}$, cholesterol, blood pressure, kidney, eye and feet checks. They help spot complications or increasing risk of complications. They also give people a chance to set some targets to work towards with their healthcare professionals. When people with diabetes go into hospital - whether it's because of their diabetes or something else - they still need the right care. That means being able to get their medication, treat their diabetes and manage their condition. Sometimes they'll be able to do this themselves, other times they'll need nurses and doctors to do this for them.

\section{What we do}

Along with the eight checks, there are other elements of care everyone with diabetes should get each year. We call them the 15 Healthcare Essentials. We make sure people know what care they should get and support them to access it. Our Clinical Champions and Shared Practice and Policy teams work together to improve care for people across the NHS whether it's in primary care (their GP or practice nurse) or with specialists or during a hospital stay.

\section{What you need to know}

There is a wealth of diabetes-related statistics. There are annual audits of care and what care people get can be drilled down to as local as a GP practice. If you'd like more help finding local statistics email stats@diabetes.org.uk 


\section{Diabetes care and care in hospitals}

\section{Infographics available}

1
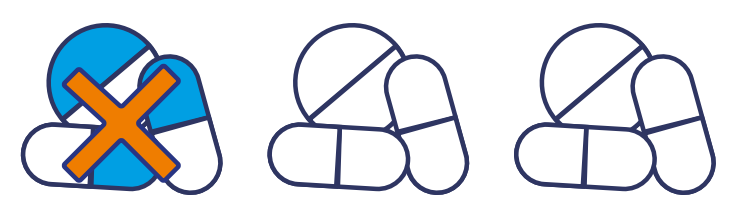

\section{Almost one in three}

people with diabetes will experience a

medication error during their hospital stay.

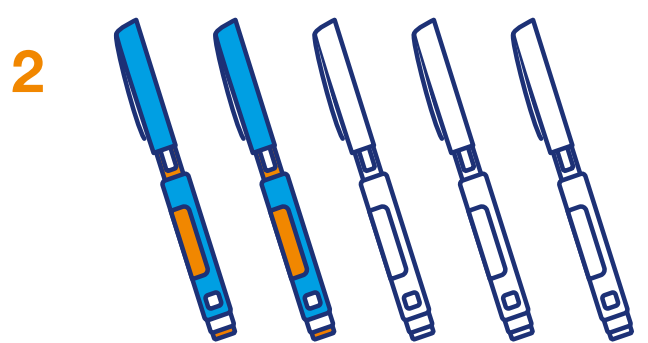

Nearly two fifths

of people treated with insulin will experience an insulin error during their hospital stay. 


\section{Diabetes care and care in hospitals}

Infographics available

3 People with diabetes should get eight basic health checks every year but

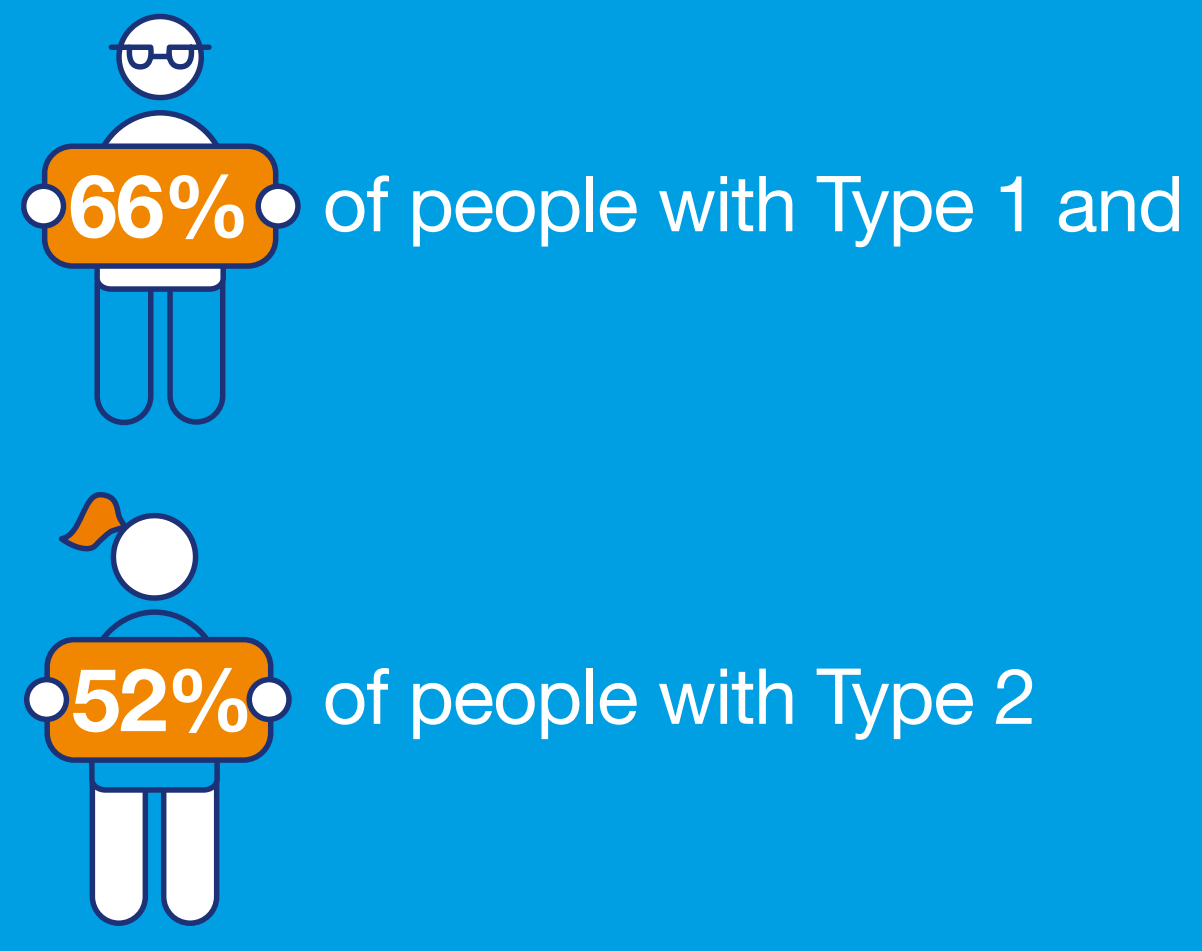

don't get them all. 


\section{Diabetes care and care in hospitals}

Infographics available

4
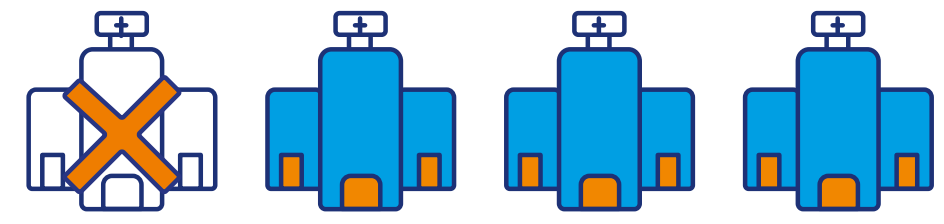

\section{More than a fifth}

of hospitals do not have a dedicated diabetes inpatient specialist nurse.

5
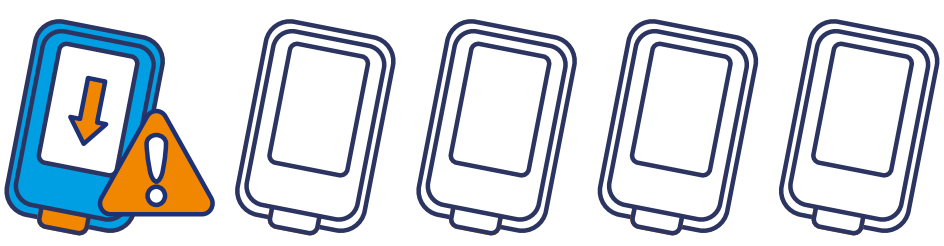

\section{Almost one fifth}

of people with diabetes will have a hypo during a hospital stay.

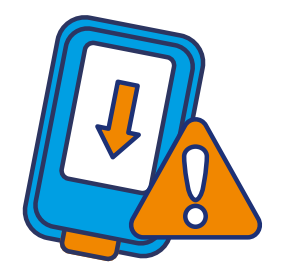

$1.3 \%$

had a severe hypo during their hospital stay. 


\section{Diabetes care and care in hospitals}

\section{Infographics available}

\section{7 \& $28 \%$ of people}

needed to see a specialist

diabetes team during their hospital stay but didn't.

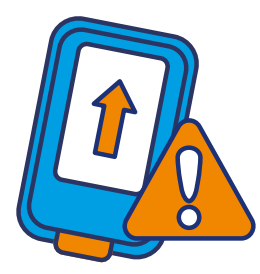

1 in 25 inpatients with Type 1 diabetes develop dangerously high blood sugars during their hospital stay.

\section{9}

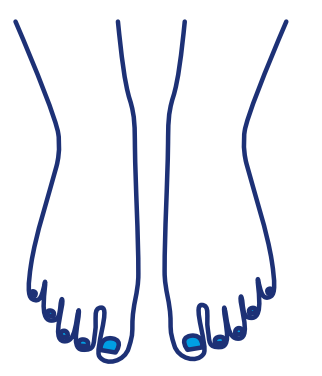

Less than two thirds

of people with serious foot problems have a proper foot check within 24 hours of being admitted to hospital. 


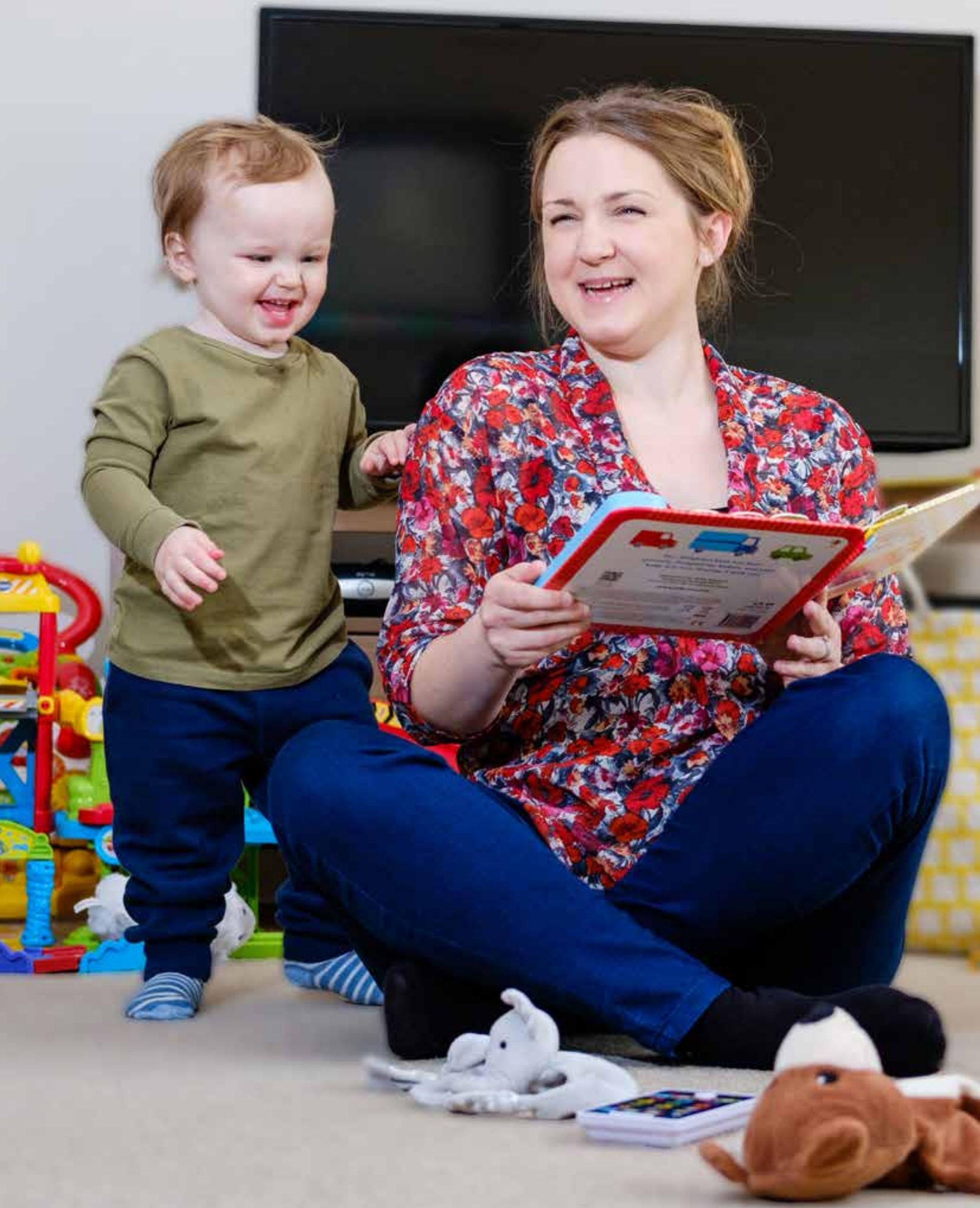




\section{Pregnancy and diabetes}

\section{(o) The basics}

Diabetes affects every part of someone's body. And it makes having a baby even more complicated. In order to have a safe pregnancy, keeping blood sugars levels as balanced as possible is even more important.

Gestational diabetes is a type of diabetes that affects pregnant women, usually during the second or third trimester. Women with gestational diabetes don't have diabetes before their pregnancy, and after giving birth it usually goes away. It's caused by the hormones produced during pregnancy which can make it difficult for your body to use insulin properly.

\section{What we do}

Our website and helpline provide women with the advice, support and information they need to have a baby. We're funding various pieces of research aimed to help women with diabetes during pregnancy. One recent successful trial helped 16 women have babies by giving them an artificial pancreas to use through their pregnancy which helped them manage their blood sugar levels far more easily. We're also funding research into gestational diabetes, including understanding its emotional impact and better supporting women to stay active through their pregnancy.

\section{Careful}

Please check with Brand and Creative before using the stats with this icon.

Think about who your work is for. 


\section{Pregnancy and diabetes}

\section{Infographics available}

1 Compared to women without diabetes, women with diabetes are:

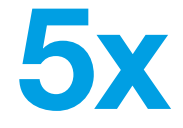

more likely

to have a

pre-term baby

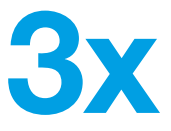

more likely to have a Caesarean section delivery

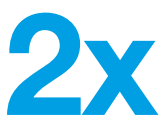

as likely to have a baby weighing more than $4 \mathrm{~kg}$.

2 Babies of women with diabetes are:

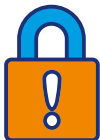

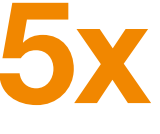

as likely to be stillborn

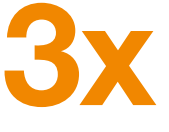

times as likely to die in their first months of life.

3

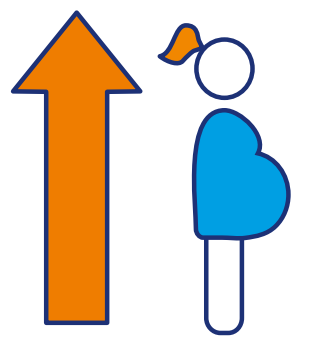

Gestational diabetes is increasing due to levels of obesity and more pregnancies in older women. 


\section{Pregnancy and diabetes}

Infographics available

$45 \%$ of the 956,861 pregnancies in the UK in 2015 involved diabetes. Of these, around:

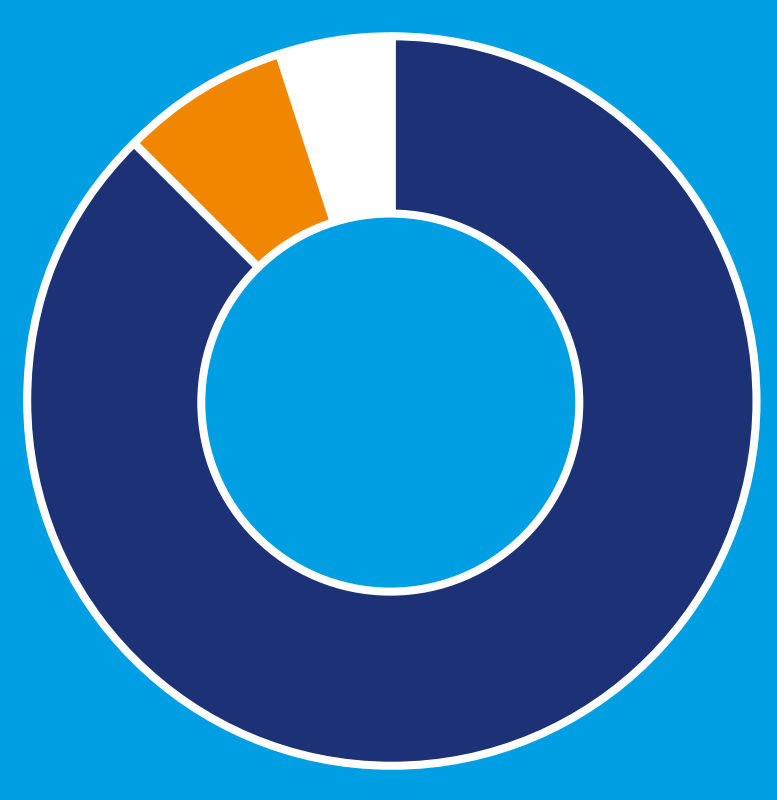

\section{2,000}

were from

gestational diabetes

\section{3,600}

were from

Type 1 diabetes

\section{2,400}

were from

Type 2 diabetes 


\section{Sex and diabetes}

\section{o The basics}

Diabetes can affect every part of the body. And that means your penis or vagina too. The reasons people with diabetes experience sexual problems are the same as any other long-term complication - high blood sugar levels, cholesterol and blood pressure. They can damage the blood vessels and nervous system causing reduced blood flow and loss of sensation in sexual organs. It can affect both women and men and everyone with diabetes should be asked whether they're having any sexual problems at their annual review. Sexual problems, particularly in men who struggle to get or keep erections, is an early sign of other complications so it's vital people don't ignore it. For people with who use insulin, hypos and sex do not go well together. And just like any other kind of exercise, sex can send people's blood sugar levels high or low.

\section{$0^{\circ}$ What we do}

Our helpline is there for anyone who's got questions, needs advice or is looking for emotional support around sex. Our social media campaign, The One, used real life stories to promote being open about sex and diabetes. Our online communities will discuss anything from whether they keep their pumps on or off and what to do the first time you have sex with a new partner when you've got diabetes.

\section{What you need to know}

Sex and diabetes is one of the few areas where we struggle for data and, similarly, there hasn't been much research into the problem either. Statistics and research are notoriously difficult to gather as it's such a personal thing. What might be a problem for one person might not be for another. 


\section{Sex and diabetes}

\section{Infographics available}

${ }^{1}+\infty \overbrace{0}^{\circ} 0$

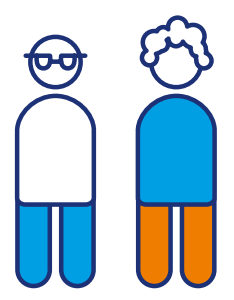

Both men and women with

diabetes are more likely to have sexual problems than people without diabetes.

$28 \infty 80$

More than one in four women with Type 1 diabetes have sexual problems.

3

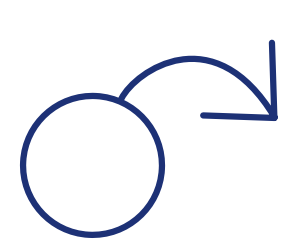

Men with diabetes are

three times more likely

to have trouble getting or keeping an

erection than men without diabetes.

4

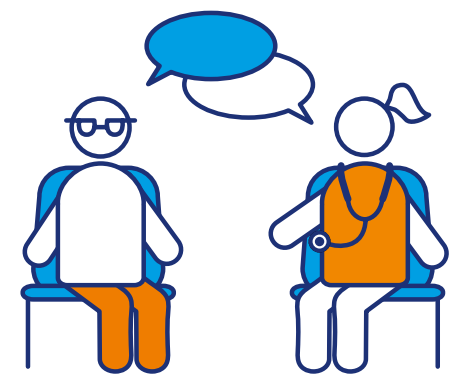

Only 15 to $20 \%$

of men are asked about sexual

problems during their annual review. 



\section{Children and diabetes}

\section{The basics}

A lot of people with Type 1 diabetes are diagnosed as children. Most children will have been quite ill beforehand. For most parents it will be a total shock. Their family's life has been turned upside down and suddenly there is an awful lot to learn very quickly. Along with coping with hypos, blood checking, and working out insulin doses, there's an emotional sledgehammer to deal with too. Even though it is no one's fault, parents often feel guilty. There's also care in school and clubs to think about and making sure their child can take part in all the other adventures of childhood. Type 2 diabetes in children is on the increase but still very rare. As with Type 2 diabetes in adults, it can be treated by lifestyle changes and, in some cases, medication.

\section{$\mathrm{R}^{\circ}$ What we do}

We make sure diabetes doesn't get in the way of being a kid. Our 4Ts campaign raises awareness of the four main symptoms (toilet, thirsty, tired, thinner) so more children are diagnosed before they're seriously ill. Our Type 1 Bag offers support and information to parents and lets them know how we can help. We convinced governments in England and Wales to change the law so children with all health conditions get the care they need in school. To help schools across the UK do this we created our Make the Grade packs, which explain what they need to do to get care right. If schools are struggling our helpline supports parents to get the care their child needs in place. Our local support groups give children and parents the chance to meet other people who are going through the same thing and learn from each other.

\section{What you need to know}

There is no way of knowing exactly how many children have Type 2 diabetes. We do know there are at least 621 children and people younger than 25 with Type 2 diabetes, under the care of specialist care diabetes units, in England and Wales. Our advocacy service is part of our helpline and supports people to solve more practical problems relating to their diabetes. We only use 'advocacy' internally. To the outside world, all the support we provide comes under the Diabetes UK Helpline. That's to keep things simple. Help is an everyday word, advocacy isn't. 


\section{Children and diabetes}

\section{Infographics available}

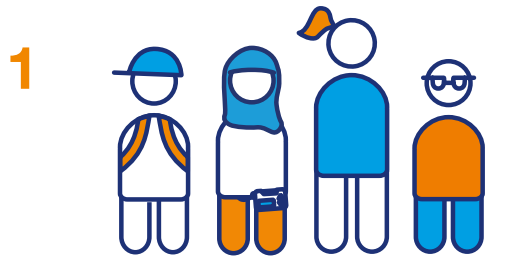

Around 40,000

children have diabetes.

2 Around $90 \%$ of children with diabetes have Type 1 diabetes.

About $10 \%$ have Type 2 and other types of diabetes like MODY, cystic fibrosis related diabetes or their diagnosis is not defined.

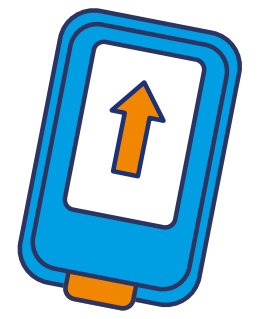

One in six

are diagnosed with diabetes in diabetic ketoacidosis (DKA). 


\section{Children and diabetes}

\section{Infographics available}

4 The first children with Type 2 diabetes

were diagnosed in the UK in the year

2000.

5
舟
Most children are diagnosed with
diabetes between the ages of
10 and 14.

6 More than 3,000

children are diagnosed with

diabetes every year. 


\section{Access to technology}

\section{o The basics}

Insulin had not even been discovered 100 years ago. Before then Type 1 diabetes was a death sentence. Living with Type 1 diabetes after 1921 required resusable steel needles. And if you wanted to check your blood sugar levels it involved a urine test and a small science experiment. Even as late as the 1980s people had to draw up their insulin from a vial using a syringe. But since then technology has made living with diabetes easier.

\section{$0^{\circ}$ What we do}

Whenever there's been a breakthrough in diabetes technology our research has normally been part of the story. In the 1970s we purchased the UK's first artificial pancreas and showed that people with Type 1 diabetes could use an insulin pump to improve their blood glucose control. In the 1980s we funded the development of the first insulin pen which has made injections easier for millions of people. In the same decade our research developed the first ever electrochemical blood glucose meter, now an essential part of diabetes management across the globe. Along with developing the technology we've fought to make sure people can benefit from it. We've pushed the government to make clear everyone with diabetes should get the test strips they need. When they don't we support them to fight any restrictions. We led a campaign to make flash monitoring - an even quicker way to check blood sugars - available on the NHS.

\section{What you need to know}

There is no data on how many people use an insulin pump or a pen. All of the data from this page is taken from our own surveys. 


\section{Access to technology}

\section{Infographics available}

1

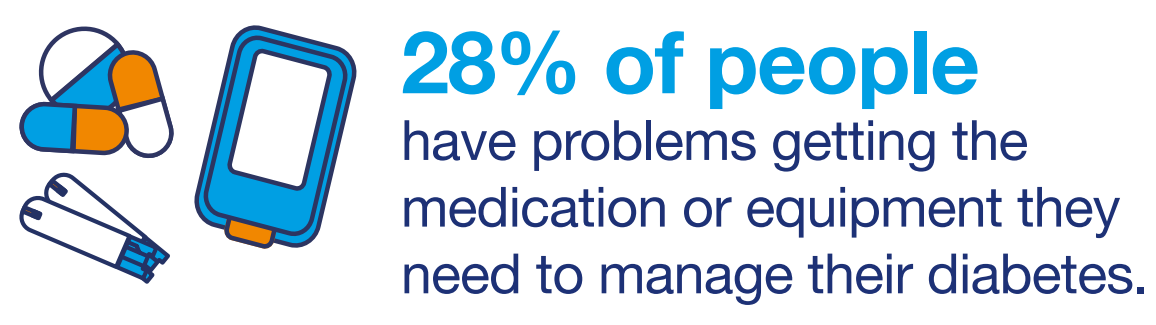

2

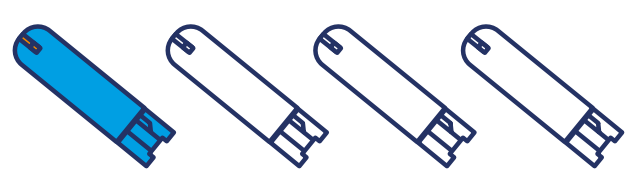

One in four

people with diabetes aren't prescribed the amount of test strips they need.

3

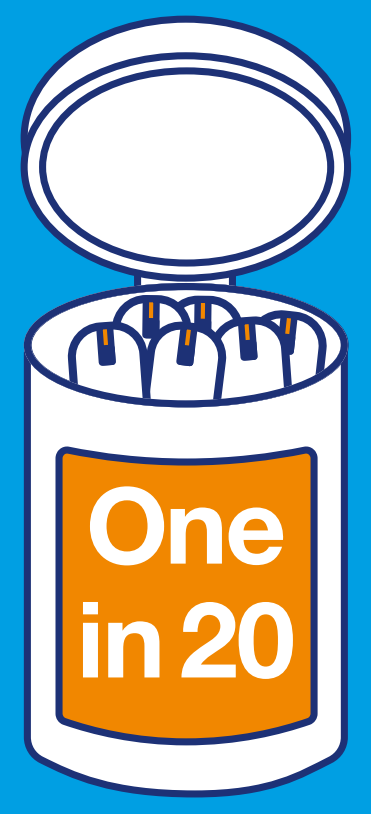

of the problems

our advocacy service dealt with in 2017

were about access to test strips. 

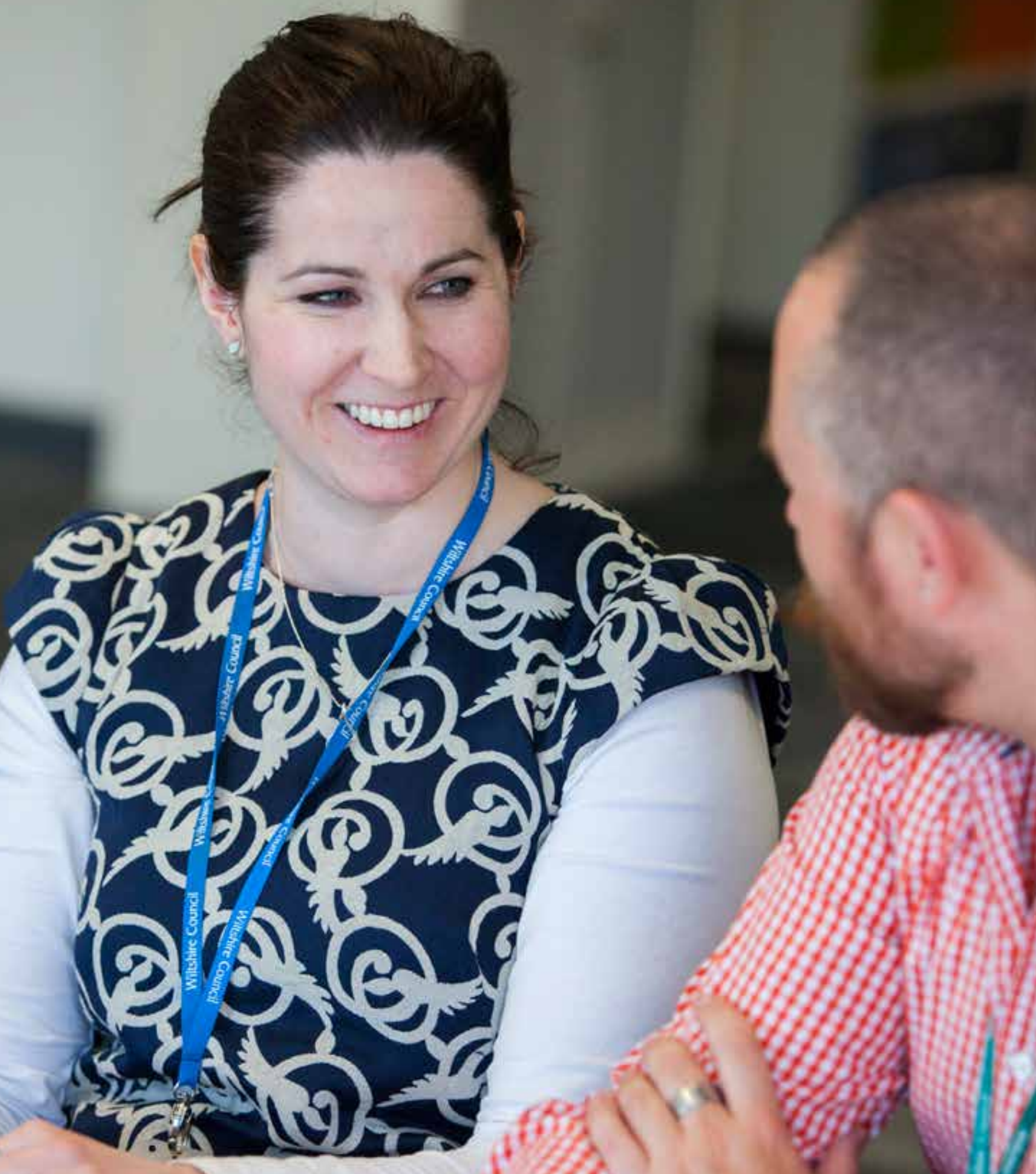


\section{Work, driving and diabetes}

\section{The basics}

Diabetes affects more than just the body. It can make work, school, driving, even going on holiday a lot harder. While not everyone with diabetes considers themselves disabled, under the eyes of the law almost everyone with diabetes - certainly everyone with Type 1 - is recognised as having a disability. This means in England, Scotland and Wales people are protected from discrimination by the Equality Act 2010 and in Northern Ireland by the Disability Discrimination Act. Some of the common problems we deal with are people not being allowed to take rest breaks after a hypo or concerns about taking time off for appointments. Issues with driving are frequent as people with diabetes must renew their license more often, a constant worry for those who drive commercially. People will lose their license if they have two serious hypos where someone is unable to treat a low themselves - in a year.

\section{What we do}

Our helpline provides people with advice about their rights and support to challenge issues caused by their diabetes. We successfully campaigned for the Driver and Vehicle Licensing Agency (DVLA) to reform their rules which were unfairly keeping some people with diabetes off the road. Thanks to our intervention serious hypos which happen when people are asleep no longer contribute to someone losing their license.

\section{What you need to know}

These statistics are taken from surveys and our helpline's record of all the people who we've helped through 2017. 


\section{Work, driving and diabetes}

\section{Infographics available}

1 People with Type 1 are twice as likely

as people with Type 2 to feel diabetes

has caused them difficulties at work.

288

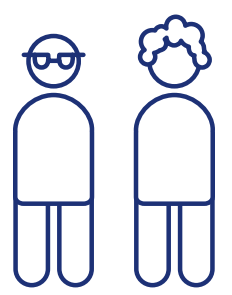

1 in 5 people

with Type 1 diabetes feel they

have faced discrimination at work.

3

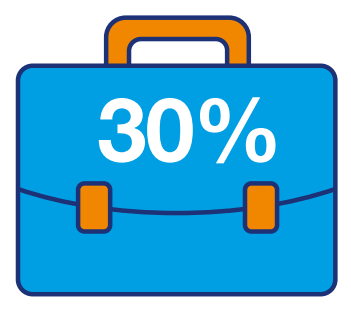

of the problems

our advocacy service dealt with in

2017 were about problems at work. 


\section{Work, driving and diabetes}

\section{Infographics available}

4

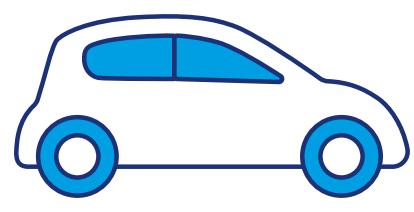

$17 \%$ of the problems

our advocacy service dealt with in 2017 were to do with driving.

5 Our advocacy service helped deal with 1,593 practical problems caused by diabetes in 2017 .

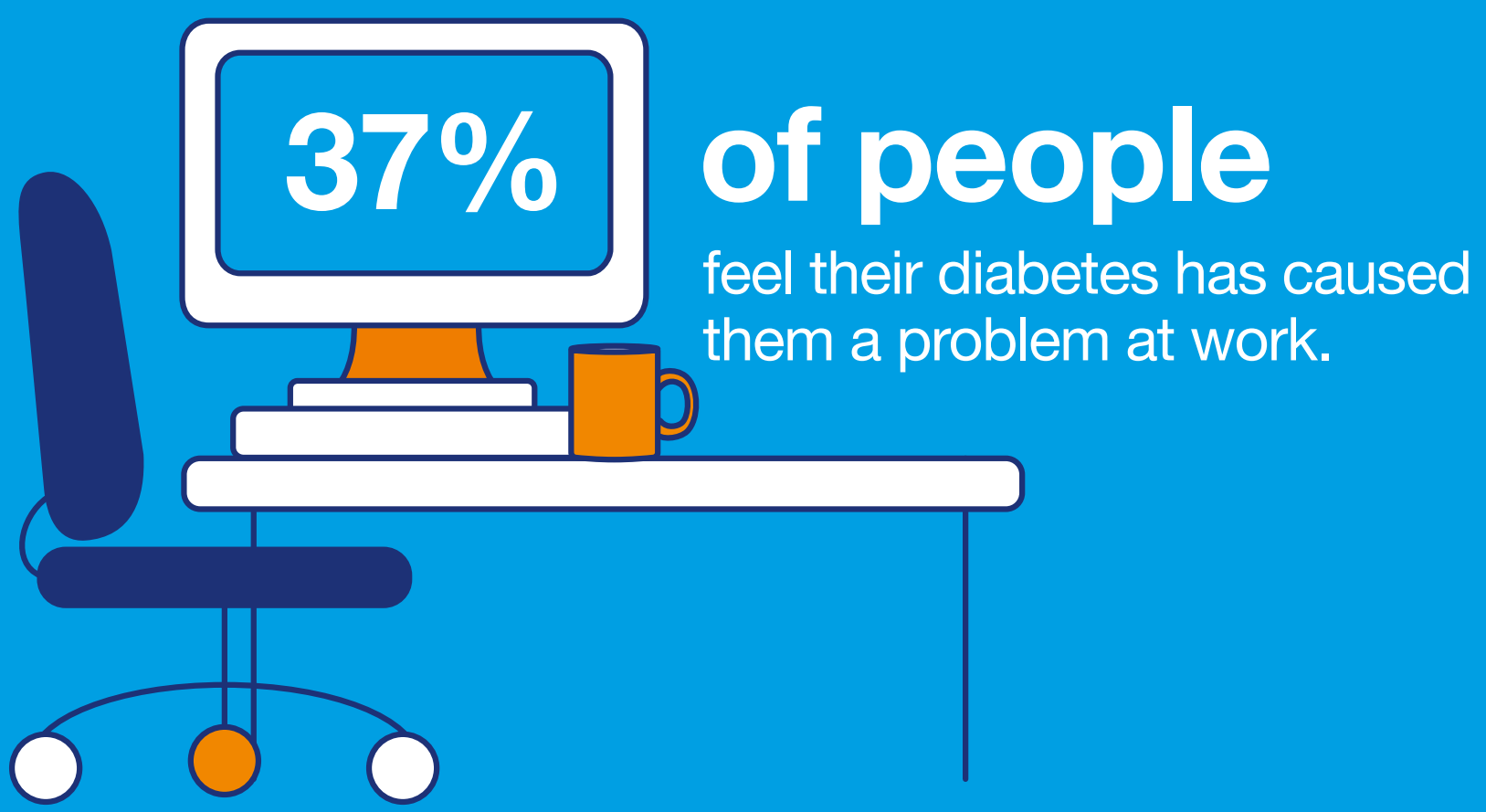




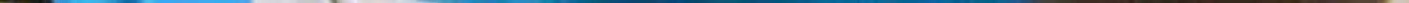




\section{Some numbers about us from 2017}

\section{Infographics available}

1 Our volunteers gave more than

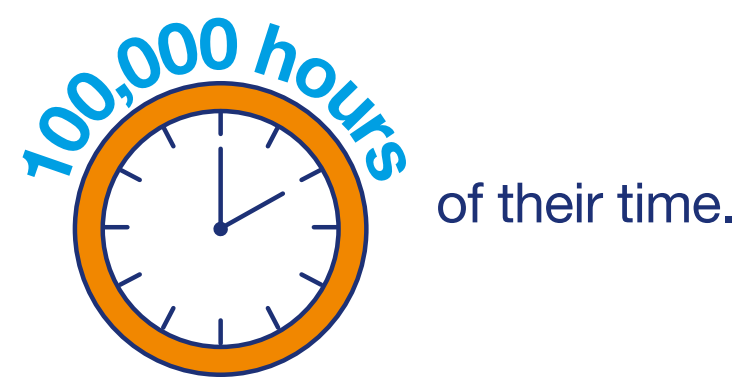

2 Our helpline counsellors offered support and advice to people

\section{5,100 times.}

3 More than

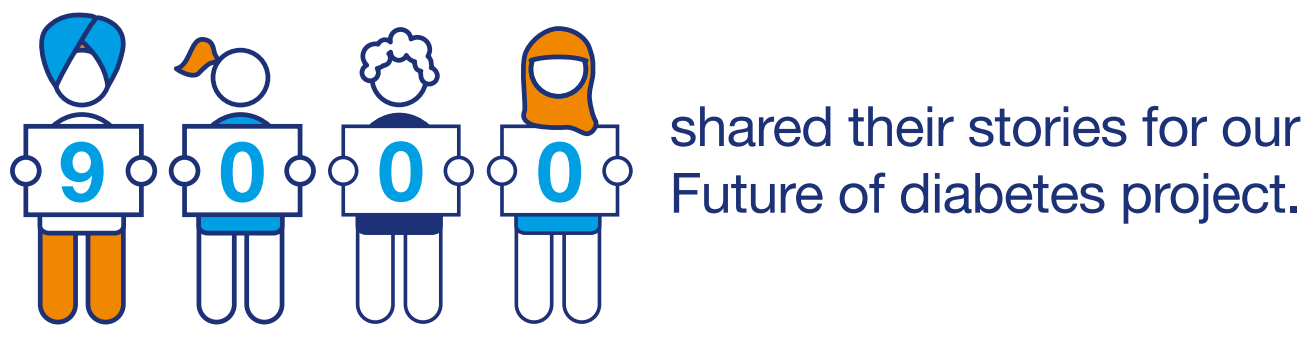

4

$$
\begin{aligned}
& \text { More than } \\
& \text { took part in our } 1 \text { Million Step } \\
& \text { Challenge and raised four times } \\
& \text { as much as } 2016 .
\end{aligned}
$$




\section{Some numbers about us from 2017}

\section{Infographics available}

5 We support people with diabetes through:

$\frac{\Theta}{1950}$ Local Groups

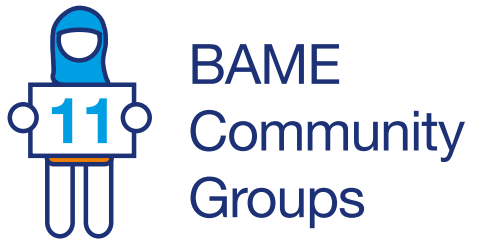

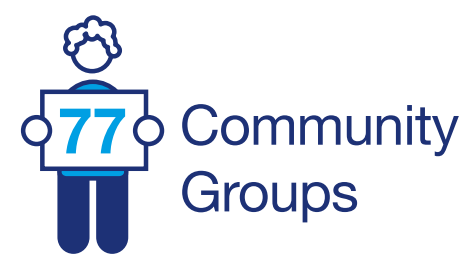

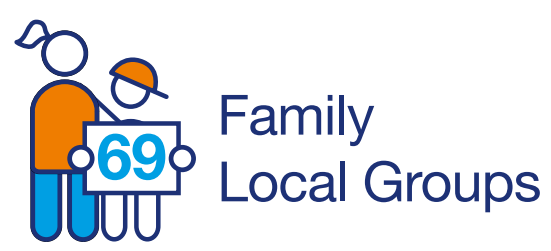

$\infty$

\$6 Young Adult

OI Community Groups.

6

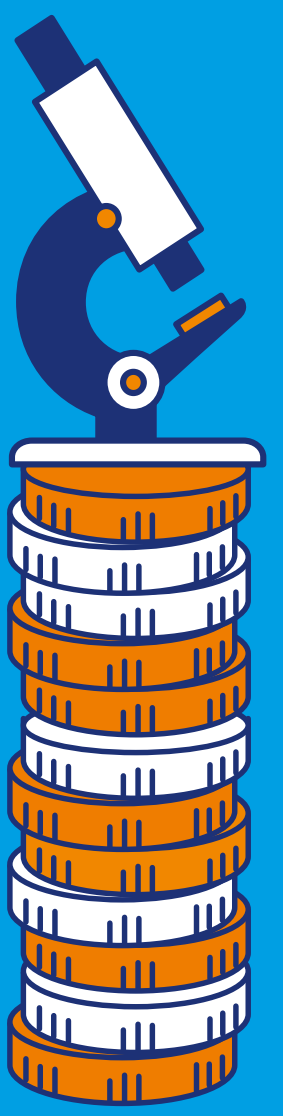

In the last 10 years

alone, we've invested

\section{¿64 millition}

in diabetes research

across the UK. 


\section{Some numbers about us from 2017}

\section{Infographics available}

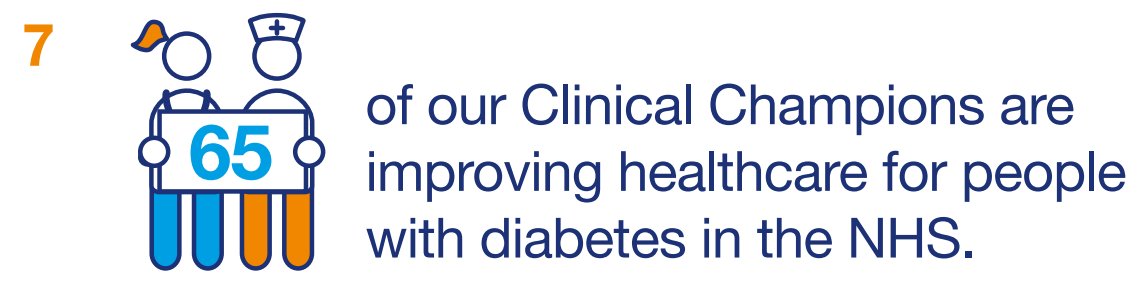

8

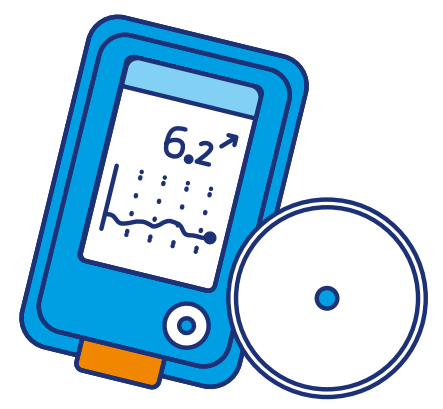

More than 4,500

people signed up to support

our Flash campaign.

Now more people have access

to truly life-transforming

technology to help manage

their diabetes.

9

More than 6,800

people joined our Food Upfront campaign demanding better labelling on food packaging.

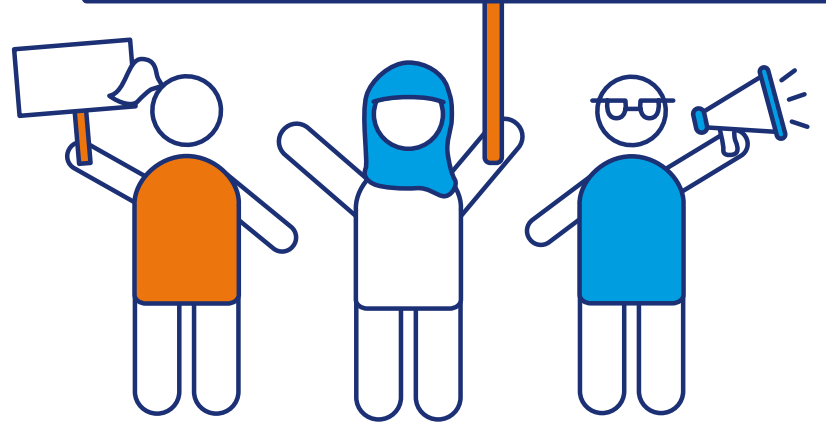




\section{Some numbers about us from 2017}

\section{Infographics available}

10

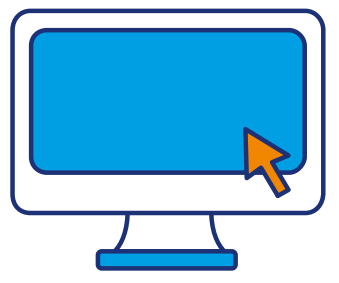

11

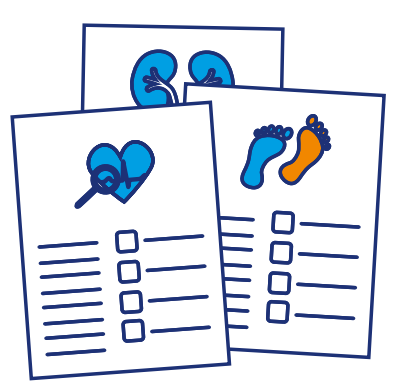

We gave

20,000 healthcare professionals

and commissioners across the UK information and practical tools for improving diabetes care in 2017.

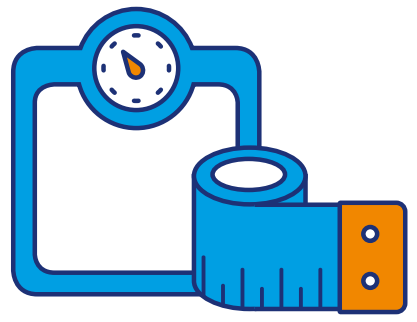

We helped

\section{5,980 people}

know their risk of Type 2 diabetes and what they can do to reduce it in 2017.

Two of people in the general population thirds would recommend us to someone. 


\section{Some numbers about us from 2017}

\section{Infographics available}

14

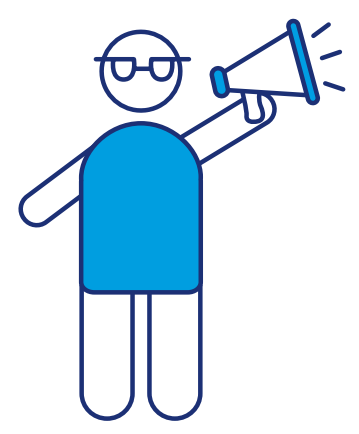

We have more than 1,500 Diabetes Voices campaigning for better diabetes care.

15 In 2017, more than

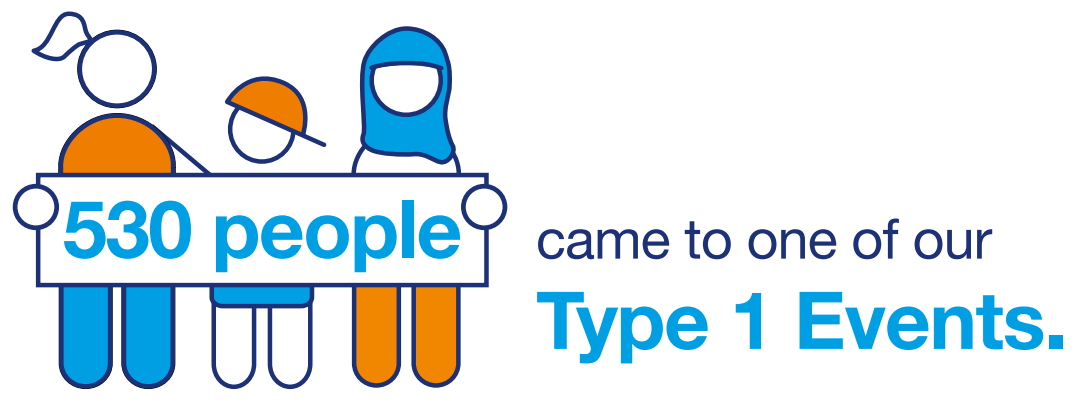

16

We raised

\section{£35.9 million.}




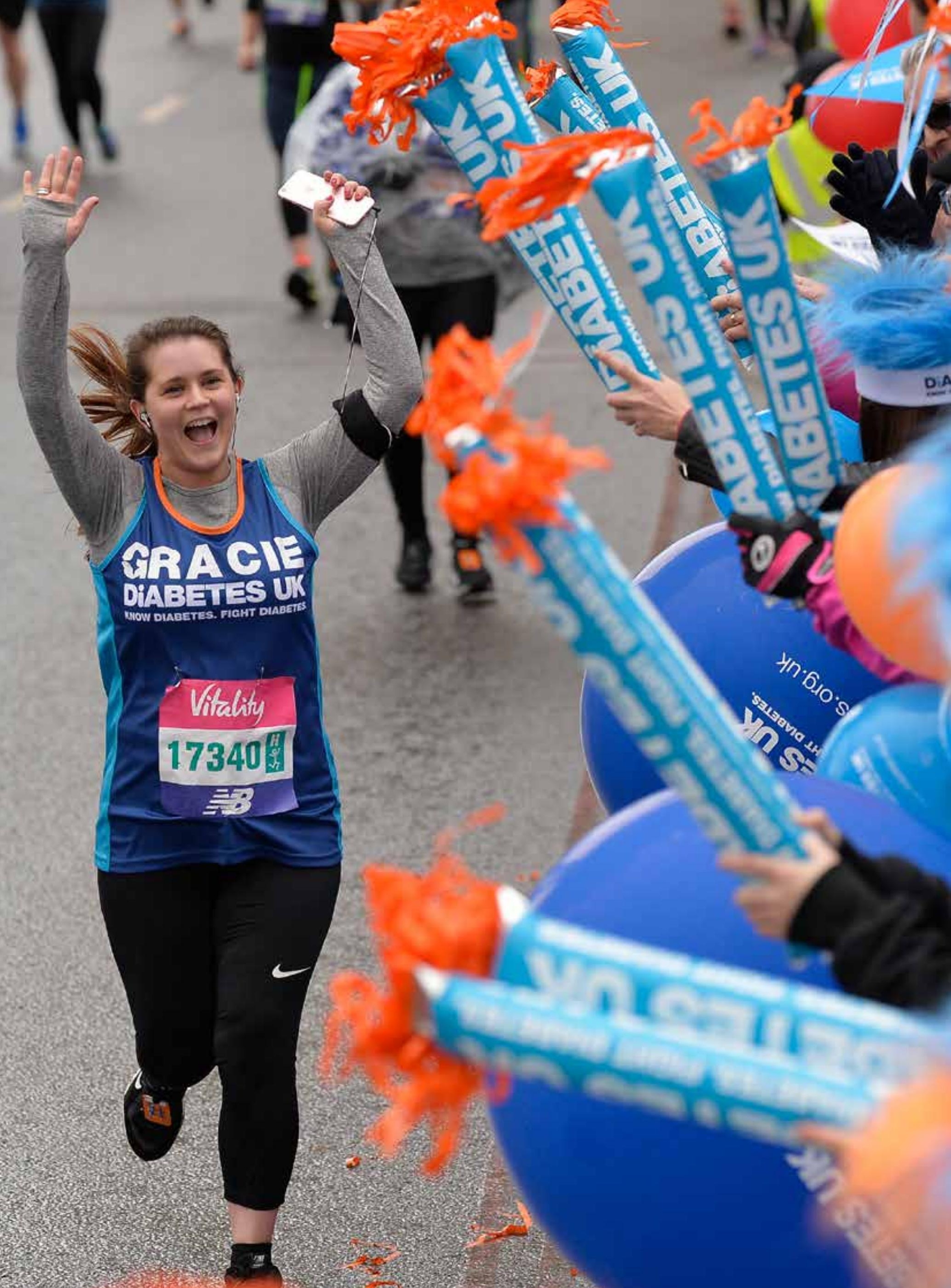




\section{What people think of us}

\section{Infographics available}

1
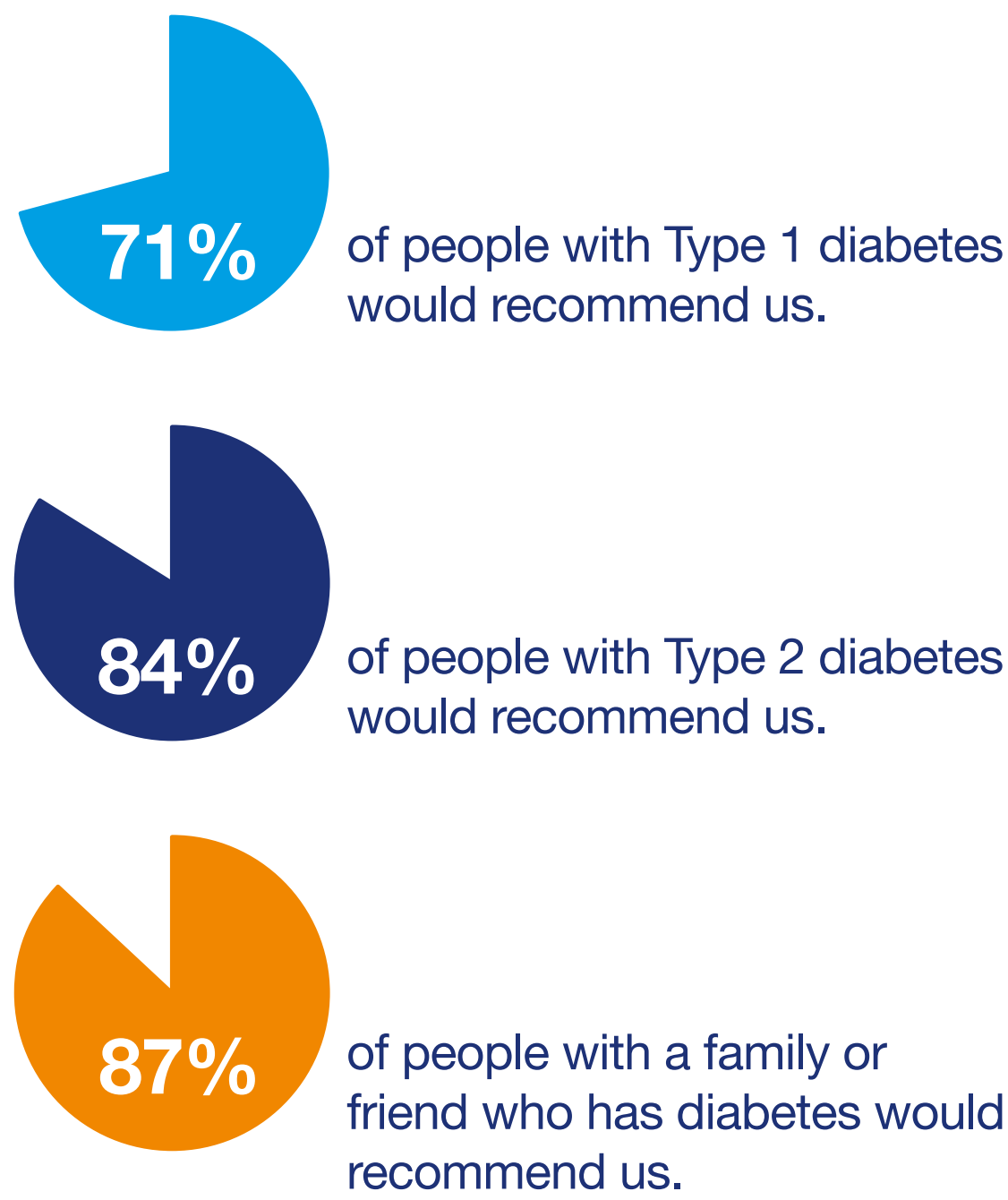

\section{What you need to know}

Fewer people with Type 1 diabetes recommending us is a historic issue and something we've worked hard to tackle over the last couple of years. We've spent more time talking about how Type 1 diabetes affects people's lives, whether that's your love life, nights out or just the general frustration of bewildering blood sugar levels. 


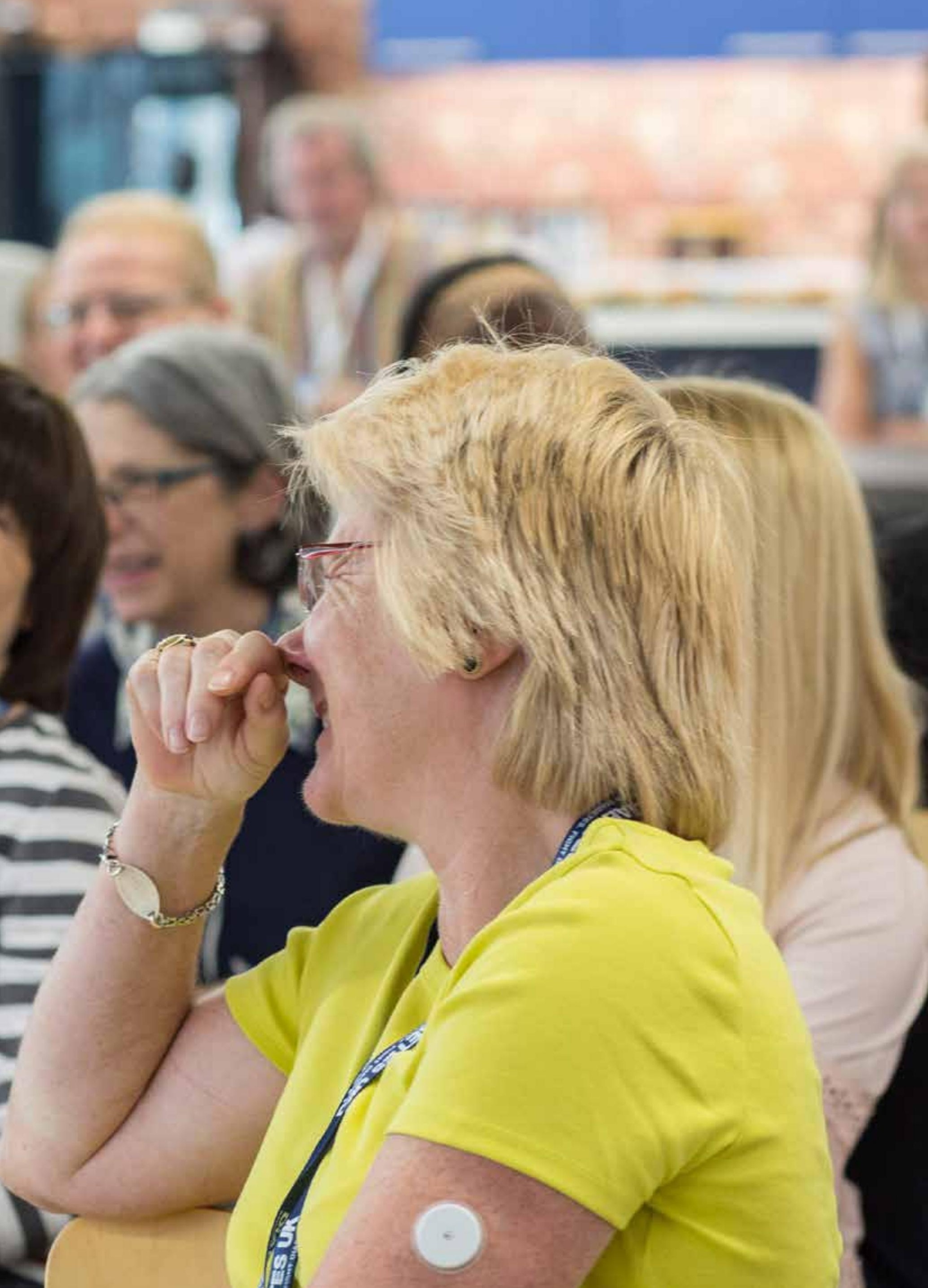




\section{What people think about diabetes}

1 Diabetes affects more people than all cancers and dementia combined.

\section{But just $17 \%$ of people think diabetes is serious.}

When the general population are asked to rank conditions based on their impact on people's health and life.

\section{5\% Cancer}

\section{$69 \%$ Alzheimer's}

$56 \%$ Heart disease

52\% Mental illness

\section{$48 \%$ Stroke}

\section{$17 \%$ Diabetes}

And that reflects people's willingness to support us.

Just $1 \%$ of the general population would pick us to donate $£ 5$ a month to.

\section{2\% Cancer Research}

\section{$20 \%$ Macmillan}

$10 \%$ British Heart Foundation

7\% Alzheimer's Society

$6 \%$ Mind

$1 \%$ Diabetes UK 


\section{What people think about diabetes}

2 The more everyone understands the damage diabetes can do the more likely they are to donate to us.

Once people know about four or more complications of diabetes we become the charity they'd most likely donate to.

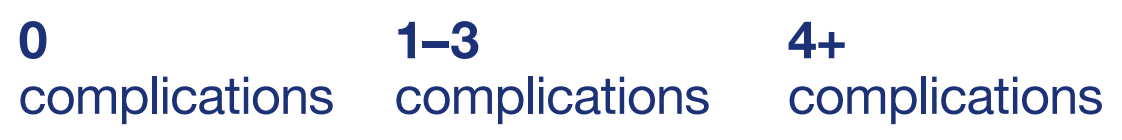

\begin{tabular}{|c|c|c|c|}
\hline Diabetes UK & $4 \%$ & $9 \%$ & $20 \%$ \\
\hline Macmillan & $19 \%$ & $22 \%$ & $18 \%$ \\
\hline Cancer Research & $22 \%$ & $20 \%$ & $17 \%$ \\
\hline Alzheimer's Society & $5 \%$ & $6 \%$ & $8 \%$ \\
\hline heart Foundatior & $9 \%$ & $8 \%$ & $6 \%$ \\
\hline
\end{tabular}

\section{What you need to know}

When we talk about the general population in these statistics we don't count people with diabetes or people with a close connection to someone with the condition. When we talk about everyone, that includes the general population and people with diabetes and people with close connections to someone with the condition. 


\section{What people think about diabetes}

3 Unprompted the following percentage of the general population could name these complications of diabetes.

\section{$25 \%$ Sight loss}

\section{$25 \%$ Amputation}

$10 \%$ Heart disease

$7 \%$ Kidney damage

6\% Foot ulcers

$6 \%$ Nerve damage

\section{$5 \%$ Death}

\section{$5 \%$ Stroke}

4\% Shorter life span

$1 \%$ Problems in pregnancy

But almost one in five people don't think diabetes is an important cause that requires support and action.

So this is why it's so important we're frank with people about the seriousness of diabetes and just what it can do. 


\section{References}

\section{Headline stats}

1 NCVIN (2016), Diabetes Prevalence Model for England + estimated growth between 2015-2020 from APHO (2010) Prevalence Models for Scotland and Wales.

2 Figure based on newly diagnosed figures from the 2011/12 and 2012/13 National Diabetes Audit, extrapolated up to the whole population with diabetes indicated by the QOF data for the equivalent years and divided by two to give an annual average.

3 UK Renal Registry 20th Annual report: 2018 www.renalreg.org/wp-content/uploads/2018/06/20thAnnual-Report web_book.pdf

4 Public Health England Outcomes Framework Indicator: 4.12iii - Crude rate of sight loss due to diabetic eye disease in those aged 12+ per 100,000 population (last accessed June 2018)

5 NHS Digital (2017), National Diabetes Audit 2015-16 Report 2A: Complications and Mortality PHE (2017) Footcare Activity Profiles 2013-2016

\section{How many people have diabetes}

1 NCVIN (2018) Diabetes Footcare Activity Profiles 2014-17

21 in 15 based on ONS population data for 2016 (65,648,054 million) with a total diabetes population of 4,595,955 million from NCVIN and AHPO prevalence models.

3 Quality and Outcomes Framework 2016-17 digital.nhs.uk/catalogue/PUB30124 Scottish Diabetes Survey 2016 www. diabetesinscotland.org.uk/Publications/Scottish\%20 Diabetes\%20Survey\%202016.pdf

Quality and Outcomes Framework 2016-17 gov.wales/statistics-and-research/general-medicalservices-contract/?lang=en

Quality and Outcomes Framework 2016-17 www.health-ni.gov.uk/publications/201617-rawdisease-prevalence-trend-data-northern-ireland

4 British Diabetic Association (1996), Diabetes in the UK, United Kingdom, London, BDA compared to 2016/17 Quality and Outcomes Framework

5 British Diabetic Association (1996), Diabetes in the UK, United Kingdom, London, BDA compared to $2016 / 17$ Quality and Outcomes Framework

6 No reference needed.

\section{The different types of diabetes}

1 HSCIC: National Diabetes Audit 2015/16: Report 1: Care Processes and Treatment Targets and NHS Scotland (2017) Scottish Diabetes Survey 2016

2 HSCIC: National Diabetes Audit 2015/16: Report 1: Care Processes and Treatment Targets and NHS Scotland (2017) Scottish Diabetes Survey 2016 


\section{Diagnosis}

1 Harris Ml, Klein R, Welborn TA et al (1992). Onset of NIDDM occurs at least 4-7 years before clinical diagnosis. Diabetes Care 15 (7); 815-819

2 Winkley, K. et al (2013) The clinical characteristics at diagnosis of type 2 diabetes in a multi-ethnic population: the South London Diabetes cohort (SOUL-D) Diabetologia (56) 1272-1281

3 Winkley, K. et al (2013) The clinical characteristics at diagnosis of type 2 diabetes in a multi-ethnic population: the South London Diabetes cohort (SOUL-D) Diabetologia (56) 1272-1281

4 RCPCH \& HQIP (2017) National Paediatric Diabetes Audit 2012-15 Report 2: Hospital Admissions

\section{How many people are at risk of Type 2 diabetes?}

1 NCVIN Diabetes Prevalence Model for England, APHO Diabetes Prevalence Model

2 NCVIN Diabetes Prevalence Model for England, APHO Diabetes Prevalence Model

3 Lindstrom, J, Louheranta, A, Mannelin, M, and for the Finnish Diabetes Prevention Study Group. The Finnish Diabetes Prevention Study (DPS): lifestyle intervention and 3-year results on diet and physical activity. Diabetes Care. 2003; 26: 3230-3236

4 Hauner H (2010). Obesity and diabetes, in Holt RIG, Cockram CS, Flyvbjerg A et al (ed.) Textbook of diabetes, 4th edition. Oxford: Wiley-Blackwell

5 Based on Office for National Statistics estimates of UK population. Estimates for UK, England and Wales, Scotland and Northern Ireland - Mid-2016): 26,031,331 adult men and 27,226,626 adult women are recorded. $22 \%$ of the men is $5,726,893$ and $24 \%$ of the women is $6,534,390$ - which is a total of $12,261,283$

$6 \mathrm{Ng} \mathrm{M}$ et al (2014) Global, regional and national prevalence of overweight and obesity in children and adults 1980-2013: a systematic analysis for the Global Burden of Disease Study 2013. Lancet 384 (9945); 766-781

$7 \mathrm{Ng} \mathrm{M}$ et al (2014) Global, regional and national prevalence of overweight and obesity in children and adults 1980-2013: a systematic analysis for the Global Burden of Disease Study 2013. Lancet 384 (9945); 766-781

8 Lindstrom, J, Louheranta, A, Mannelin, M, and for the Finnish Diabetes Prevention Study Group. The Finnish Diabetes Prevention Study (DPS): lifestyle intervention and 3-year results on diet and physical activity. Diabetes Care. 2003; 26: 3230-3236

9 Health and Social Care Information Centre (2006). Health Survey for England 2004, Health of Ethnic Minorities and Ntuk, U.E., Gill, J.M.R., Mackay, D.F., Sattar N. \& Pell, J.P. (2014). Ethnic-Specific Obesity Cufoffs for Diabetes Risk: Cross-sectional Study of 490,288 UK Biobank Participants. Diabetes Care 37(9), 2500-7

10 Vaxillaire M and Froguel, $\mathrm{P}$ (2010). The genetics of Type 2 diabetes: from candidate gene biology to genome-wide studies, in Holt RIG, Cockram CS, Flyvbjerg A et al (ed.) Textbook of diabetes, 4th edition. Oxford

11 Mclellan, KCP et a (2014) Therapeutic interventions to reduce the risk of progression from prediabetes to type 2 diabetes mellitus. Therapeutics And Clinical Risk Management. Albany: Dove Medical Press Ltd, v. 10, p. 173-188, 2014.

12 Department of Health (2011) Physical Activity Guidelines for adults (19-64 years): Factsheet 4

13 Department of Health (2011) Physical Activity Guidelines for adults (19-64 years): Factsheet 4

14 British Heart Foundation Centre on Population Approaches for Non-Communicable Disease Prevention. Nuffield Department of Population Health, University of Oxford: 2015 bhf physicalactivity-statistics-2015feb.pdf 


\section{Diabetes and the NHS}

1 Hex, N., et al (2012) Estimating the current and future costs of Type 1 and Type 2 diabetes in the United Kingdom, including direct health costs and indirect societal and productivity costs. Diabetic Medicine. 29 (7) 855-862

2 NHS Digital (2018) National Diabetes Inpatient Audit 2017

3 NHS Digital (2018) National Diabetes Inpatient Audit 2017

4 Hex, N., et al (2012) Estimating the current and future costs of Type 1 and Type 2 diabetes in the United Kingdom, including direct health costs and indirect societal and productivity costs. Diabetic Medicine. 29 (7) 855-862

5 Sampson MJ, Doxio N, Ferguson B et al (2007). Total and excess bed occupancy by age, speciality

6 NHS Digital (2017) Prescribing for Diabetes, England - 2006/07 to 2016/17

$7 \mathrm{Hex}, \mathrm{N}$., et al (2012) Estimating the current and future costs of Type 1 and Type 2 diabetes in the United Kingdom, including direct health costs and indirect societal and productivity costs.

Diabetic Medicine. 29 (7) 855-862

8 www.england.nhs.uk/2018/03/type-2-nhsdpp/

\section{Heart attacks, stroke and cardiovascular disease}

1 NHS Digital (2017) National Diabetes Audit Report 2A: Complications and Mortality Royal College of Physicians Sentinel Stroke National Audit Programme (SSNAP). National clinical audit annual results portfolio March 2015-April 2016. Available: bit.ly/1M5R30p

2 NHS Digital (2017) National Diabetes Audit Report 2A: Complications and Mortality Royal College of Physicians Sentinel Stroke National Audit Programme (SSNAP). National clinical audit annual results portfolio March 2015-April 2016. Available: bit.ly/1M5R30p

3 NHS Digital (2017) National Diabetes Audit Report 2A: Complications and Mortality Royal College of Physicians Sentinel Stroke National Audit Programme (SSNAP). National clinical audit annual results portfolio March 2015-April 2016. Available: bit.ly/1M5R30p

4 NHS Digital (2017) National Diabetes Audit Report 2A: Complications and Mortality Royal College of Physicians Sentinel Stroke National Audit Programme (SSNAP). National clinical audit annual results portfolio March 2015-April 2016. Available: bit.ly/1M5R30p

5 Royal College of Physicians Sentinel Stroke National Audit Programme (SSNAP). National clinical audit annual results portfolio March 2015-April 2016. Available: bit.ly/1M5R30p

6 NDA 2015-16 Report 2A Mortality and Complications

7 NHS Digital (2017), National Diabetes Audit 2015-16 Report 2A: Complications and Mortality 


\section{Amputations}

1 NCVIN (2018) Footcare Activity Profile 2014-17

2 Holman N, Young RJ, Jeffcoate WJ. Variation in the incidence of amputation of the lower limb in England; Diabetologia 2012

3 Kerr, M (2017) Diabetic Foot Care In England: An Economic Study

4 Kerr, M (2017) Diabetic Foot Care In England: An Economic Study

5 Kerr, M (2017) Diabetic Foot Care In England: An Economic Study

6 NCVIN (2018) Footcare Activity Profile 2014-17

\section{Sight loss}

1 Public Health England Outcomes Framework Indicator: 4.12iii - Crude rate of sight loss due to diabetic eye disease in those aged 12+ per 100,000 population (last accessed June 2018)

2 The State of the Nation: Eye Health 2016 RNIB

3 Leamon, S. Davies, M (2014) Number of adults and children certified with sight impairment and severe sight impairment in England and Wales: April 2012-March 2013; RNIB and Moorfields

4 Liew, G et al. (2014) A comparison of the causes of blindness certifications in England and Wales in working age adults (16-64 years), 1999-2000 with 2009-2010. BMJ Open 2014;4:e004015

5 Liew, G et al. (2014) A comparison of the causes of blindness certifications in England and Wales in working age adults (16-64 years), 1999-2000 with 2009-2010. BMJ Open 2014;4:e004015

6 Mathur (2017) Diabetic eye disease. A UK Incidence and Prevalence Study - RNIB

7 Mathur (2017) Diabetic eye disease. A UK Incidence and Prevalence Study - RNIB

8 Scanlon PH (2008). The English national screening programme for sight threatening diabetic retinopathy. Journal of Medical Screening 15 (1); 1-4

\section{Kidney disease}

1 UK Renal Registry 20th Annual report: 2018 www.renalreg.org/wp-content/uploads/2018/06/20thAnnual-Report web_book.pdf

2 UK Renal Registry 18th Annual Report: 2016 www.renalreg.org/wp-content/uploads/2015/01/ web book 07-04-16.pdf

3 NHS Digital (2017), National Diabetes Audit 2015-16 Report 2A: Complications and Mortality

4 NHS Digital (2017), National Diabetes Audit 2015-16 Report 2A: Complications and Mortality

5 NHS Digital (2017), National Diabetes Audit 2015-16 Report 2A: Complications and Mortality 


\section{Mental health and depression}

1 Mommersteeg, PM et al. (2013) The association between diabetes and an episode of depressive symptoms in the 2002 World Health Survey: an analysis of 231,797 individuals from 47 countries. Diabetic Med. Jun;30(6): 208-214

2 Peyrot M, Rubin RR, Lauritzen T et al (2005). Psychosocial problems and barriers to improved diabetes management: results of the Cross-National Diabetes Attitude, Wishes and Needs (DAWN) Study. Diabetic Medicine 22; 1379-1385

3 Diabetes UK Future of Diabetes report www. diabetes.org.uk/resources-s3/2017-11/1111B\%20 The\%20future\%200f\%20diabetes\%20report FINAL .pdf

4 Mental Health Taskforce (2016). The Five Year Forward View for Mental Health: A report from the independent Mental Health Taskforce to the NHS in England

5 Diabetes UK Helpline stats email (no reference needed)

6 Mezuk, B et al. (2008) Depression and Type 2 Diabetes Over the Lifespan: A meta-analysis. Diabetes Care 31 (12) 2383-2390

7 Diabetes UK (2015). 15 Healthcare Essentials online survey 2015. Baseline: 3000 responses

\section{Management of diabetes}

1 Diabetes UK Future of Diabetes report www. diabetes.org.uk/resources-s3/2017-11/1111B\%20 The\%20future\%20of\%20diabetes\%20report FINAL .pdf

2 NHS Digital (2018) National Diabetes Audit Report 1: Care Processes and Treatment Targets 2016-17

3 NHS Digital (2018) National Diabetes Audit Report 1: Care Processes and Treatment Targets 2016-17

4 NHS Digital (2018) National Diabetes Audit Report 1: Care Processes and Treatment Targets 2016-17

5 Diabetes education: the big missed opportunity diabetes-resources-production. s3-eu-west-1.amazonaws.com/diabetes-storage/migration/pdf/Diabetes\%2520UK Diabetes\%2520education\%2520-\%2520the\%2520big\%2520missed\%2520opportunity updated\%2520June\%25202016.pdf

6 Diabetes education: the big missed opportunity diabetes-resources-production. s3-eu-west-1.amazonaws.com/diabetes-storage/migration/pdf/Diabetes\%2520UK Diabetes\%2520education\%2520-\%2520the\%2520big\%2520missed\%2520opportunity updated\%2520June\%25202016.pdf

7 Diabetes education: the big missed opportunity diabetes-resources-production. s3-eu-west-1.amazonaws.com/diabetes-storage/migration/pdf/Diabetes\%2520UK Diabetes\%2520education\%2520-\%2520the\%2520big\%2520missed\%2520opportunity updated\%2520June\%25202016.pdf

8 Department of Health (2007). Working together for better diabetes care. Clinical case for change: Report by Sue Roberts, National Director for Diabetes 


\section{Diabetes care and care in hospitals}

1 NHS Digital (2018) National Diabetes Inpatient Audit 2017

2 NHS Digital (2018) National Diabetes Inpatient Audit 2017

3 NHS Digital (2018) National Diabetes Audit 2016/17

4 NHS Digital (2018) National Diabetes Inpatient Audit 2017

5 NHS Digital (2018) National Diabetes Inpatient Audit 2017

6 NHS Digital (2018) National Diabetes Inpatient Audit 2017

7 NHS Digital (2018) National Diabetes Inpatient Audit 2017

8 NHS Digital (2018) National Diabetes Inpatient Audit 2017

9 NHS Digital (2018) National Diabetes Inpatient Audit 2017

\section{Pregnancy and diabetes}

1 CEMACH (2007). Diabetes in pregnancy: are we providing the best care? Findings of a national enquiry www.publichealth.hscni.net/sites/default/files/Diabetes\%20in\%20Pregnancy-\%20are\%20 we\%20providing\%20the\%20best\%20care.pdf

2 CEMACH (2007). Diabetes in pregnancy: are we providing the best care? Findings of a national enquiry www.publichealth.hscni.net/sites/default/files/Diabetes\%20in\%20Pregnancy-\%20are\%20 we\%20providing\%20the\%20best\%20care.pdf

3 Dornhorst, A and Banerjee, A (2010). Diabetes in Pregnancy, in Holt RIG, Cockram CS, Flyvbjerg A et al (ed.) Textbook of diabetes, 4th edition. Oxford: Wiley-Blackwell

$4 \quad$ NICE guideline [NG3]. Diabetes in pregnancy: management from preconception to the postnatal period. Published date: February 2015. Last updated: August 2015

Office for National Statistics: Conceptions in England and Wales 2015 www.ons.gov.uk/ peoplepopulationandcommunity/birthsdeathsandmarriages/conceptionandfertilityrates/bulletins/ conceptionstatistics/2015

\section{Sex and diabetes}

1 Price, D. Sexual Function in Men and Women with Diabetes. Chapter 49 in Holt R et al Textbook of Diabetes Fifth edition 2016

2 Enzlin P, Mathieu C, Van den Bruel A et al (2003). Prevalence and predictions of sexual dysfunction in patients with Type 1 diabetes. Diabetes Care 26; 409-414

3 Johannes CB, Araujo AB, Feldman HA, Derby CA, Kleinman KP, McKinlay JB. Incidence of erectile dysfunction in men 40 to 69 years old: longitudinal results from the Massachusetts male aging study. J Urol. 2000;163(2):460-463. [PubMed]

4 Hackett G, Cole N, Bhartia M et al (2014). The response to testosterone undecanoate in men with Type 2 diabetes is dependent on achieving threshold serum levels (the BLAST study). International Journal of Clinical Practice 68 (2); 203-215 


\section{Children and diabetes}

1 HQIP and RCPCH (2018) National Paediatric Diabetes Audit 2016/2017 Care Processes and Outcomes www.rcpch.ac.uk/sites/default/files/2018-07/npda annual report 2016 - 2017 april 2018 final updated 2.pdf (England and Wales: 27,720 have Type 1 diabetes); NHS Digital (2018) National Diabetes Audit 2016-17 (England and Wales: 3763 have Type 2 and other diabetes); NHS Scotland (2017) Scottish Diabetes Survey 2016 www.diabetesinscotland.org.uk Publications/Scottish\%20Diabetes\%20Survey\%202016.pdf (Scotland: 3535); Table of children diagnosed Type 1 at January 2014.Northern Ireland Childhood Register at Queen's University. (Northern Ireland: 1133 under the age of 18 - estimated to be 1,200 as newly diagnosed 15,16 and 17 year olds aren't included in the register). National Paediatric Diabetes Audit figures for children diagnosed with Type 2 diabetes appears to be an underestimate therefore we have used National Diabetes Audit figures for a more accurate representation.

2 HQIP \& RCPCH: National Paediatric Diabetes Audit Report 2015-2016

3 RCPCH \& HQIP (2017) National Paediatric Diabetes Audit 2012-15 Report 2: Hospital Admissions and NHS Digital (2018) National Diabetes Audit 2016-17, NHS Scotland (2017) Scottish Diabetes Survey 2016. Based on figures from the NPDA we estimate around $2 \%$ of all children diagnosed with diabetes have other types of diabetes such as MODY, cystic fibrosis related diabetes etc.

4 HQIP \& RCPCH: National Paediatric Diabetes Audit Report 2015-2016 Part 1: Care Processes and Outcomes

5 HQIP \& RCPCH: National Paediatric Diabetes Audit Report 2015-2016 Part 1: Care Processes and Outcomes and Scottish Diabetes Survey 2016

6 Diabetes UK Advocacy stats (no reference needed).

\section{Access to technology}

1 Diabetes UK Future of Diabetes report www. diabetes.org.uk/resources-s3/2017-11/1111B\%20 The\%20future\%200f\%20diabetes\%20report FINAL .pdf

2 Diabetes UK Test strips report diabetes-resources-production.s3-eu-west-1. amazonaws.com/diabetes-storage/migration/pdf/1092 Testing\%2520times test\%2520strips\%2520and\%2520meters\%2520report\%2520WEB\%2520final.pdf

3 Diabetes UK Advocacy stats (no reference needed).

\section{Work, driving and diabetes}

1 Diabetes UK Future of Diabetes report www. diabetes.org.uk/resources-s3/2017-11/1111B\%20 The\%20future\%200f\%20diabetes\%20report FINAL .pdf

2 Diabetes UK Future of Diabetes report www. diabetes.org.uk/resources-s3/2017-11/1111B\%20 The\%20future\%200f\%20diabetes\%20report FINAL .pdf

3 Diabetes UK Advocacy stats (no reference needed).

4 Diabetes UK Advocacy stats (no reference needed).

5 Diabetes UK Advocacy stats (no reference needed).

6 Diabetes UK Future of Diabetes report www. diabetes.org.uk/resources-s3/2017-11/1111B\%20 The\%20future\%200f\%20diabetes\%20report FINAL .pdf 
Some numbers about us from 2017

1-16 Diabetes UK annual report 2017 www. diabetes.org. uk/about us/annual-reports

\section{What people think of us}

1 Wave 1 - Walnut Diabetes Brand Tracker

\section{What people think about diabetes}

1-3 Wave 1 - Walnut Diabetes Brand Tracker 